\title{
The Nature, Logic, and Significance of Strong Communities for Children
}

\author{
Published online: 28 May 2020 \\ (C) Springer Nature Switzerland AG 2020
}

Gary B. Melton ${ }^{1,2}$ (D) Jill D. McLeigh ${ }^{1,3}$

\begin{abstract}
High levels of stress and low levels of support for parents have significant implications for child safety, particularly for families living in neighborhoods which are dangerous and disadvantaged. Building on this knowledge about the causes and correlates of child maltreatment, the U.S. Advisory Board on Child Abuse and Neglect (1993) recommended a neighborhood-based child protection strategy. This article describes Strong Communities for Children, a community-based child maltreatment prevention intervention designed to carry out the Board's recommendations. During an initial period of development and evaluation (lasting more than 7 years) of the first such initiative (located in communities near Greenville, SC), Strong Communities added substantially to the knowledge base on the role of community factors in children's safety. It also advanced understanding of ways to operationalize some of the ideas underlying the Board's proposed strategy. This article (a) describes the conceptual foundation, the logic model, and the engagement strategies that comprise Strong Communities; (b) provides an overview of the results from the first
\end{abstract}

\footnotetext{
The authors were employed at Clemson University, while the Strong Communities for Children initiative was undertaken in parts of three counties in northwestern South Carolina from 2002 to approximately 2009.

The examples and research discussed are drawn from the initial implementation of the Strong Communities model, which was the first comprehensive operationalization of the strategy proposed by the U.S. Advisory Board on Child Abuse and Neglect (1993). Hence, past tense is used in most of this article, in order to describe the process, anecdotes, and evaluation data as they developed in Strong Communities in South Carolina in the 2000s. However, Strong Communities remains a distinctive approach that can be adapted for use in other communities (see, e.g., Strong Communities Israel, which has been fully implemented, for example, in selected neighborhoods in Tel Aviv (Katz et al. 2019; McLeigh et al. 2017) and which relies in those instances on social work students from Tel Aviv University in combination with community volunteers).

Strong Communities in South Carolina was supported by a generous grant from The Duke Endowment to the Clemson University Research Foundation (Gary B. Melton, principal investigator). The opinions expressed herein are not necessarily those of The Endowment, its advisors, staff, or trustees.

Melton was a member of the U.S. Advisory Board on Child Abuse and Neglect from 1989 to 1993 (vice-chair, 19911993). He was the lead author of the Board's reports on its proposed national strategy for child protection (U.S. Advisory Board 1993) and the related proposal for the federal role (U.S. Advisory Board 1991), among other Board documents. The opinions expressed in this article do not necessarily reflect those that were held by the Board as a whole.
}

Gary B. Melton

gary.melton@cuanschutz.edu

Extended author information available on the last page of the article 
comprehensive initiative; (c) discusses their significance; and (d) concludes with discussion of the possibilities for Strong Communities in the current context.

Keywords U.S. Advisory Board on Child Abuse and Neglect · Strong Communities for Children · Child abuse · Child neglect · Prevention · Logic models · Generational trends

The child protection system in the USA and much of the remainder of the world grew from a classic article more than a half-century ago by Henry Kempe and his colleagues (Kempe et al. 1962) in Denver. In their article positing a battered-child syndrome, Kempe and colleagues reported research (surveys of prosecutors and hospital emergency departments) suggesting that a few hundred cases of parent-inflicted child maltreatment (i.e., physical abuse) occurred in a year in the USA. Given the relatively small number of children believed to be affected and the purported simplicity (albeit egregiousness) of the problem, their proposed solution involved case-finding. Kempe and his colleagues advocated successfully for mandatory reporting, an approach enacted quickly state by state and then a bit more slowly country by country. Although varying somewhat from state to state, these laws required that certain professionals working with children (e.g., physicians, social workers, teachers, childcare providers) report suspected child maltreatment. In 1974, the Congress passed the landmark Child Abuse Prevention and Treatment Act (CAPTA). At the outset, to receive federal funds from CAPTA, states were required to have provisions for reporting and investigation of child maltreatment, a legal requirement that all states had already adopted. Initially, no such requirements existed in federal law for prevention or treatment.

\section{Causes, Nature, and Scope of Child Maltreatment}

Kempe et al.'s (1962) research and the subsequent policy response greatly increased awareness of child maltreatment, especially physical and sexual abuse. Experience has shown, however, that the assumptions regarding the scope and scale of child maltreatment that guided his article and the corollary enactment of mandated reporting laws were largely erroneous (Melton 2005). Advances in research since Kempe et al.'s sentinel article have shown that child maltreatment results from a complex array of stressors, such as lack of community cohesion (Kim 2015; Maguire-Jack and Showalter 2016; Weissbourd and Grimm 1981), low levels of parental self-efficacy (Cochran and Woolever 1983), absence of social supports (Giovanni and Billingsley 1970; Thompson 1995, 2015; Turner and Avison 1985), and changing family dynamics (Melton and Thompson 2002; U.S. Department of Health and Human Services (DHHS) 2016. Furthermore, child maltreatment occurs when families are faced with multiple challenges that are personal, social, and economic in nature (e.g., Finkelhor and Jones 2006; Jack 2000; Maguire-Jack and Font 2017; Pelton 2015). Mounting evidence has suggested that increasing stress and declining support for parents have significant implications for child safety, particularly for families living in neighborhoods which are dangerous and disadvantaged (e.g., Coulton et al. 1999; Garbarino and Kostelny 1992; McDonell and Melton 2008; Molnar et al. 2016; Zolotor and Runyan 2006). Instead of resulting from easily identifiable syndromes, as proposed in Kempe et al.'s article, most reported cases of child maltreatment involve chronic, complex, and 
multi-problem situations in which neglect or emotional abuse is present. Even for physical and sexual abuse, the idea that syndromes are causal factors has been discounted (see, e.g., Wolfe 1985).

Despite increased understanding of the etiology of child maltreatment, the policy approach has remained largely the same. Indeed, the basic approach has become stronger, as mandatory reporting requirements have become more expansive (e.g., in some states, all citizens are mandatory reporters). These changes are the causes in part of the enormous increases in the caseloads of Child Protective Service (CPS) agencies. The number of recorded reports of suspected child maltreatment skyrocketed from a few hundred in the early 1960s to 1.1 million in 1980 (U.S. Department of Health and Human Services 1988) to more than 3.5 million in 2018 (U.S. Department of Health and Human Services 2020)—numbers that are conservative because of their omission of "screened-out" reports.

As Mathews (2015) summarized in his overview of the history of reporting laws:

Kempe et al.'s research was accompanied by intensive lobbying for legislative reform. As a result, the first mandatory reporting laws were enacted in every state of the USA (except Hawaii) between 1963 and 1967. In accordance with the scope of Kempe's work at this time, these laws were initially limited to requiring medical professionals to report suspected serious physical injury inflicted by a child's parent or caregiver. The fundamental premise was that doctors regularly encounter children by virtue of their profession, and because of this are well placed to identify cases of severe maltreatment, and by reporting it enable intervention by welfare agencies to interrupt the abuse and facilitate health rehabilitation and other services for the child and family. (p. 5, citations omitted).

One might expect that the initial focus on physical abuse as reported by health professionals reflected a prescient understanding of the overload that would come from expansion of the concept of child abuse and the list of mandated reporters. However, associates of Kempe believe that such a strategic calculation did not occur (D. Bross, personal communication, April 6, 2020; B. Fraser, personal communication, April 6, 2020). Other forms of child maltreatment had simply not yet been "discovered."

Thus, when Kempe (1978) reported his discovery of sexual abuse in an award address (published but not delivered because of a heart attack during the night before the scheduled event) at the meeting of the American Academy of Pediatrics, his approach was closely analogous to the one he had taken in his exposé of the battered-child syndrome (Kempe et al. 1962) — presentation of a small number of cases. In the lecture with a title identifying sexual abuse as "another hidden pediatric problem," Kempe (1978) implied that he believed that sexual abuse should be reported to child welfare authorities as child abuse. He referred to "massive" underreporting (p. 383 ), although he did not directly address the policy question. He did make clear that he believed that treatment goals should trump the desire for retribution in the criminal justice system.

Making the link from the battered-child syndrome to sexual abuse, Kempe (1978) also noted a belief that sexual abuse in the mid-1970s was "just as common as physical abuse and the failure-to-thrive syndrome" (p. 382). This statement confirms Bross's 
(personal communication, April 6, 2020) impression that failure to thrive was the only form of neglect that was commonly considered at the time. Unlike most neglect, failure to thrive (the product of inadequate nutrition) is manifest by physical signs (principally low weight) that may be associated with physical threats to a child's survival (e.g., neurological, cardiac, and respiratory problems) as well as disabilities adversely affecting cognitive and psychomotor development. Hence, failure to thrive is easily framed as a medical problem.

Krugman (2019) has suggested that Kempe's advocacy of mandated reporting laws for health professionals "to report to Child Welfare" may have caused "the health system to view abuse and neglect as a "social problem"' (p. 1765). Tragically, the "solution" to health professionals' inattention to child abuse soon overwhelmed social service agencies as child protection was broadened to include most problems of inadequate care - issues of inequality and indecency that are typically grounded in the larger society. Ironically, the re-conceptualization divorced child maltreatment from the health system's cultural commitment to research and its political and financial resources for meeting that commitment.

Most egregiously from Krugman's (2019) perspective, “most health professionals view their role as mandatory reporters and not as part of the team that needs to be treating as well as preventing child abuse and neglect in their patients" (p. 1765). We would go further to say that mandated reporting has caused not only many health professionals but also many in the other relevant professions (e.g., educators) and the community as a whole to confuse the statutory duty to report suspected child maltreatment (in combination with state social workers' corollary statutory duty to receive and investigate such reports) with the moral duty to fulfill children's right to personal security (Melton 2005). Thus, the common belief is that after a report is made, one's responsibility has been fulfilled and indeed that further action would interfere with CPS workers' legitimate authority.

Tragically, therefore, the very system that was intended to facilitate child protection has long undermined both the helping professions' mission and the community's capacity to be guardians of children's safety and well-being:

After decades of injunctions to report cases of suspected child maltreatment to CPS, both the general public and the relevant professions equate child protection with reporting and investigation. Child protection is perceived, therefore, as primarily the responsibility of CPS. This perception ironically and tragically diminishes the safety of children, given (a) the multiplicity of problems (and, therefore, the need for diverse sources of help) that typically are present in child maltreatment (especially neglect) cases, (b) the impossibility of constant monitoring of families by CPS, and (c) the probable reduction in direct action by the general public and by professionals outside CPS to reduce risk to children. Child protection is now perceived by most adults as a coercive dramatic act, not a part of everyday life.

CPS itself is diverted from the task of increasing the safety of children. It is largely engaged instead, as a matter of legal obligation, in evidence gathering and preparation of actual or potential court cases. Attention to children's own security 
is diminished as workers spend their time checking off boxes in regard to parental conduct. By law, social workers' time is focused first and foremost on the question of "What happened?", not "What can we do to help?" (Melton 2005, pp. 13-14).

The U.S. Advisory Board expressed agreement with these observations and their importance:

The most serious shortcoming of the nation's system of intervention on behalf of children is that it depends upon a reporting and response process that has punitive connotations and requires massive resources dedicated to the investigation of allegations....As a result, it has become far easier to pick up the telephone to report one's neighbor for child abuse than it is for that neighbor to pick up the telephone and receive help before the abuse happens. (1990, p. 80).

The result of the current design of the child protection system is that investigation often seems to occur for its own sake, without any realistic hope of meaningful treatment to prevent the recurrence of maltreatment or to ameliorate its effects, even if the report of suspected maltreatment is validated. (1993, pp. 9-10, emphasis in the original).

In short, both the categories of mandated reporters and the categories of reportable maltreatment increased in law, custom, or both. The most notable example is neglect, the dominant category today and to a large extent a proxy for social need in general. Periodically, child maltreatment has also expanded to include problems of special interest in particular settings and points in time: e.g., Baby Doe cases (instances in which life-sustaining medical treatment or nourishment is withheld from a child with disabilities); children exposed to intimate partner violence; children exposed to illegal substances during the prenatal period; and children whose maltreatment is known to clergy hearing confessions. It was unsurprising to find parallel, often dramatic increases in the number of reports as CPS investigations became the avenue for addressing numerous problems of health and social welfare in addition to "battering."

\section{The U.S. Advisory Board on Child Abuse and Neglect: Toward a New National Strategy}

In response to the crisis already evident in the child protection system, the U.S. Advisory Board on Child Abuse and Neglect was established by federal statute in 1988. (For more information on the Board's development and process, see MetrikinGold (2015)). Considering the growing body of research on the nature, frequency, and causes of child maltreatment, the Board declared that the existing policy response was ineffective. The Board noted the sheer scope of the problem (2.4 million reports of suspected abuse and neglect were recorded in 1989) and expressed regret over the billions of dollars being spent on a system that failed to protect children.

The Board concluded that child abuse and neglect in the USA constituted a national emergency (U.S. Advisory Board 1990) and subsequently called for a new national 
child protection strategy (U.S. Advisory Board 1993). In so doing, the Board lamented, "The most serious shortcoming of the nation's system of intervention on behalf of children is that it is reactive and investigatory in nature instead of proactive and preventative..." (U.S. Advisory Board 1993, p. ix). The report cited the work of several researchers who pointed to the need for a broader approach to prevention of child maltreatment (e.g., Barry 1994; Belsky 1980; Garbarino and Kostelny 1992; Melton 1992; National Commission on Children 1991; Schorr 1988).

The Advisory Board recommended a public health approach to child maltreatment prevention that focused on changing community environments rather than targeting only those individuals deemed to be at risk in some way. To reduce maltreatment and increase child well-being, the report called for the creation of caring communities built on an ethic of mutual assistance.

The Board's proposed strategy reframed child protection so that, rather than focusing their attention on the question of when and how the government should intervene coercively, the principal inquiry became a broader child-centered question: "What can government and social and neighborhood institutions do to prevent or ameliorate harm to children?" (U.S. Advisory Board 1993, p. 11). To that end, the U.S. Advisory Board (1993) advocated for a neighborhood-based system of protection, whereby "all American adults... resolve to be good neighbors - to know, watch, and support their neighbors' children and to offer help when needed to their neighbors' families" (p. 82).

\section{Strong Communities for Children}

Building on the Board's recommendation that child protection should be a part of everyday life, Strong Communities for Children seeks to ensure that every child and every parent can be confident that someone will notice and someone will care whenever they have reason to celebrate, worry, or grieve. The first effort to implement this strategy occurred in parts of three counties in northwestern South Carolina. (For another detailed description of the approach, see Kimbrough-Melton and Melton (2015)). The Strong Communities service area encompassed communities diverse in population density, residential stability, race, national origin, and wealth. The Institute on Family and Neighborhood Life at Clemson University administered Strong Communities, and The Duke Endowment generously funded the effort.

Strong Communities was designed to promote normative change in perceptions, beliefs, and behavior. It sought to build both a sense of community and efficacy by focusing on four key concepts derived from the Board's reports. First, the core strategy involved the creation of caring communities, whereby community members are attentive to the needs of others around them and practice neighborliness. Second, communities should be inclusive, such that all families have access to support and are treated with respect and caring. Third, optimism was another key concept underlying the initiative. To motivate protective care for children, community members should believe that individually and collectively their actions on behalf of families will be effective. They should experience that the community is a welcoming and supportive place and that positive things do happen for families in the community. Fourth, actions should be undertaken that foster both moral (i.e., the belief that the possibility of effective action on behalf of families should be 
translated into practical activity) and social (i.e., the belief that such practical activity will occur) norms supportive of children's safety.

The design and implementation of Strong Communities did not mirror that of a typical program for prevention of child maltreatment. Thus, for example, Strong Communities emphasized primary prevention, although it also attended to families of diverse needs. Along those lines, the bumper-sticker slogan emphasized "keep [ing] kids safe" rather than helping children after abuse has already occurred. Also, Strong Communities took a universal approach ("Leave No Family Outside!"). Thus, the initiative was community-wide (not limited to a particular high-need subpopulation or neighborhood).

Strong Communities started from the premise that, to be effective, child protection must be a part of everyday life. Help must occur naturally in the institutions of everyday life (e.g., businesses; religious organizations; civic clubs; fire departments; municipal governments; neighborhood associations; pediatric and family health clinics; police departments; schools). Strong Communities was never envisioned as merely an administrative reform to facilitate coordination of services; rather, it was conceived as a movement. It was not a program but an initiative. It involved changing the way people interacted and lived their everyday lives.

\section{The Logic Model}

Underlying these distinct traits of Strong Communities was the basic principle that people should be able to get help where they are, when they need it, with ease and without stigma. In other words, people shouldn't have to ask! Although a simple message, the type of cultural transformation required was both grand and complex. Given the comprehensive and multifaceted nature of such an endeavor, Strong Communities developed a four-phase logic model to help guide the effort.

Phase 1 involved spreading the word among community leaders and community residents. This phase focused primarily on relationship-building and on educating the community about social trends and their relations to child maltreatment. The goal was to build connections in the community and increase awareness.

As members of the community began to understand the causes of child maltreatment, phase 2 was introduced. This phase involved mobilizing the community by increasing community discussion and action, and by building structures to facilitate natural helping. The first several years of the initiative sought to build a strong foundation for neighbor-to-neighbor involvement by establishing neighborhood associations, community watch groups, and other neighborhood-based associations, and by staging neighborhood festivals, block parties, and other special events (see MurphyBerman et al. (2008) for more details).

As the community and neighborhood organizations began to themselves organize these events, the natural next step (phase 3) sought to build on this foundation to increase resources for families. This phase involved developing universal means of enlistment of families of young children. It also involved the creation of new organizational commitments to support families.

The final phase (phase 4) sought to institutionalize the provision of such resources. This phase consisted of building on the relationships that had been developed and concentrating efforts to ensure ongoing and sustainable activities. Strategies employed 
included using organizations already engaged in Strong Communities to reach out to additional organizations, providing training and technical assistance to organizations, and connecting organization to one another.

It is important to note that this logic model did not flow neatly from one phase to the next. Rather, the arrows were multidirectional. Thus, while some sectors of the community were at the stage of increasing resources, other sectors were hearing the message for the first time. Furthermore, although a community may have been at the stage of increasing resources, given the natural changes within community life (e.g., families move in and out; leadership changes), there was always a need to reintroduce and remind people of the initiative's message.

\section{Strategies for Engagement}

\section{Community Mobilization}

To reach the final phase in the logic model, Strong Communities employed two strategies: community mobilization and direct service provision. Community mobilization efforts were led by outreach workers. These individuals were charged with mobilizing communities - all sectors, all ages, both genders, and multiple ethnicities - to fulfill children's right to personal security. In keeping with the logic model, outreach workers relied on existing community assets and ultimately engaged thousands of volunteers. Their success in finding new roles for community organizations (e.g., a fire station as a location for an after-school program) enabled the introduction of the second component, the provision of direct services. (For in-depth discussions of outreach workers' engagement in Strong Communities, see Berman (2020) and McLeigh et al. (2020)).

\section{Direct Service Provision}

Strong Families, the umbrella term used to describe the direct service components of Strong Communities, was introduced at the end of 2005 ( 3 years after the onset of the initiative), as the overall initiative began to move into the third phase of the logic model. Strong Families sought to provide connections with individual families of young children for the purpose of support and direct assistance. Specifically, the aim was for all families of children under the age of 6 in the Strong Communities service area to have access to someone, whether paid or volunteer, who would watch out for them. An important feature of Strong Families was that families joined Strong Communities; they were not referred.

Strong Families sought (a) to build or strengthen a family's social support network; (b) to encourage mutual support, parent leadership, and reciprocity; and (c) where needed, to provide or arrange for professional support and direct services. As with the mission of Strong Communities, Strong Families was premised on universality. Thus, in addition to building on existing connections, staff focused on three key sectors with the greatest potential to reach all families - health care facilities, schools, and community organizations. These points of entry made it easier for families of very young children to connect through organizations they trusted and to do so at settings of everyday life. 
Within the health sector, a nurse employed by Strong Communities (Clemson University) focused on engaging pediatric and obstetric physicians to enroll families and to place a priority on parent support as a part of anticipatory guidance provided to expectant moms and infants. Fact sheets and handouts were also developed for physicians to share with the families in their care. Finally, Strong Families provided physicians with the opportunity to contact a family advocate (a Strong Communities staff member with mental health credentials) for home- and community-based support to parents who needed more than the typical level of support.

The second point of entry for enrolling families was public kindergarten programs for 4- and 5-year-olds. In partnership with local schools and spearheaded primarily by family advocates, families were enrolled in Strong Families during the screening process, received home visits during the summer months, and offered parent-child and parent-focused activities during the school year. In addition to providing more traditional mental health services to families who needed such support, the family advocates connected families to informal support and helped them to expand their networks. For example, at the beginning of the school year, a family advocate brought parents together for an activity while the teachers were welcoming the children to their new school. The family advocate had the parents place pushpins on a map to show where they lived. Parents were then encouraged to connect with those who lived near them for child-care exchanges and other support. Other types of informal support included giving information about organizations and activities in the community and creating new forums for connection to other parents and support persons. One family advocate started a grandparent support group in recognition of the large number of families within the school consisting of grandparents raising grandchildren.

The third point of entry was community organizations (e.g., fire departments, churches, apartment complexes, real estate agencies, and law enforcement agencies). In addition to asking these organizations to enroll families, Strong Communities staff called recruited community organizations to offer activities designed to engage parents. Consistent with the premise that services are best provided where families live and work, community organizations and their leaders (many of whom were already Strong Communities volunteers) were recruited to develop family activities in their local community.

Most often, the organizations and individuals developing Family Activity Centers (FACs) were also the service providers. In addition to setting-specific services, the services offered through all of the FACs included:

- play groups, which provided a chance for children to spend time playing together while parents socialized with other parents;

- parent-child activities, which were designed for parents and their children to spend time together in fun family activities (e.g., scrapbooking; crafts);

- parents' nights out/moms' mornings out, in which child care with fun learning activities was provided so parents could enjoy an evening out or caregivers could have time to run errands or spend time with friends;

- financial education and counseling, which consisted of workshops on money management combined with consultation from a banker or a financial planner; 
- chats with a family advocate, in which a volunteer human service professional helped families find resources to meet their needs.

By building on the relationships established with community organizations, Strong Families was able to add two additional direct service efforts aimed at addressing the root causes of child maltreatment, particularly neglect. One focused on children of prisoners and provided mentors for the children and connected parents, caregivers, and younger siblings of the children to supportive services (e.g., respite care; childcare; legal services; job training; economic assistance and counseling). The other, Safe Families (see Melton and Anderson 2008), provided supplementary support in acute and/or crisis situations. Beginning early in 2009, Safe Families, which was modeled after an effort undertaken by Lydia Home in Chicago, was introduced in the service area. The goal was to help parents and families in resolving challenges and making needed life changes by connecting them to supportive services and community resources. Safe Families sought to help families build a strong and lasting network of individual, family, and community support, and, when needed, provided temporary inhome care for children during a period of family crisis or a major challenge.

\section{Results}

In reviewing the principles and logic of the Strong Communities initiative and some of its key components, the question naturally arises as to whether it was successful. First, a caveat must be given that although 7+ years is long in terms of a typical grant cycle, it is not a long time when the focus is on transformation in the way individuals live their everyday lives-overcoming a generations-old trend of decreasing social capital and building new cultural norms. (Although grant support was year to year, Strong Communities was intended to be a decade-long effort. However, funding ended prematurely during the Great Recession.) Survey data collected at the outset of the initiative suggested that approximately one-fifth of parents of young children were highly isolated-uninvolved in attending community activities, helping neighbors, or being helped by them; unable to identify sources of emergency childcare; and unfamiliar with children in the neighborhood other than their own. In some measure, such lack of support often reflects parents' own disconnection from community institutions. Although research indicates that there has been a substantial decrease in community crime (Colen et al. 2016) and sexual exploitation (Finkelhor et al. 2015) in recent years, there has been a generations-long trend toward markedly increasing alienation, isolation, and distrust (Twenge et al. 2014). More generally, society is structured in a way that does not allow for easily noticing when others in their community need help. In addition to the lack of structures for noticing and supporting parents, young parents experience a more rushed pace of life and high rates of mobility that do not allow for extended family to add support in child-rearing.

With that said, the evaluation accounted for the fact that measuring the effects of Strong Communities would be a complex, long-term endeavor. Multiple studies were 
carried out using quantitative, qualitative, and mixed methods. The evaluation included both process and outcome components.

\section{Process Evaluation}

The process evaluation involved measuring volunteer and organizational activity and Strong Families participation. Volunteer recruitment and activity served as a proxy measure for community engagement. During the course of the initiative, more than 5000 volunteers contributed approximately $70,000 \mathrm{~h}$ of service. ${ }^{1}$ As seen in Figs. 1 and 2 , the number of volunteers and the amount of time contributed increased steadily over time. In addition, volunteers remained active with the initiative for longer periods of time as the initiative progressed (see Table 1).

The involvement of community organizations was critical because of the importance of the settings of everyday life for instituting normative change and for sustaining new norms. As shown in Fig. 3, Strong Communities engaged 188 businesses, 213 faith communities, and 85 voluntary organizations (e.g., special interest groups, such as garden clubs; neighborhood associations; service clubs) —along with all of the local governments, all of the public safety agencies, many of the health clinics, most of the schools and child care centers, and many other community institutions (e.g., apartment complexes; community centers; libraries; parks). This engagement increased steadily over the course of the initiative.

Faith communities were among the most fruitful sources of volunteers (for details, see McLeigh et al. 2020; Melton and Anderson 2008). This phenomenon was especially pronounced among exceptional volunteers, the $40+$ volunteers who were nominated by outreach staff as being repeated and creative major catalysts for new projects in Strong Communities, an impression confirmed by interviews with volunteers (Hashima and Melton 2008). Typically presenting a lifelong commitment to community service and an embrace of both the nature and the scale of Strong Communities' goals, more than one-fourth were church employees, and more than $90 \%$ reported attending religious services at least weekly during the preceding year. Moreover, the sense of commitment to the community and the initiative was also a feature, even if less remarkable, of "regular" volunteers recruited from churches. Among the various sectors involved in Strong Communities, the length of retention of volunteers from churches was second only to those recruited through fire departments, a much smaller but especially volunteer-minded group (see Haski-Leventhal and McLeigh 2009).

In an effort to track the number of families reached by Strong Families and to maintain contact with them, enrollment cards were distributed, collected, and recorded in a database. Overall, more than 4000 families enrolled and thousands more

\footnotetext{
${ }^{1}$ A case-based volunteer data system was launched in January 2004. Until then, 799 individuals (unduplicated count) and 828 unidentified individuals (mostly people who had volunteered to participate in group activities) had been recorded as contributing time to Strong Communities. These numbers are included in the total, but detailed information about these volunteers is not known. Furthermore, because much activity that is an outgrowth of Strong Communities was conducted without the participation of an outreach worker or a volunteer leader, even such an expanded number is an underestimate of the true prevalence of volunteer activity within the scope of the initiative.
} 


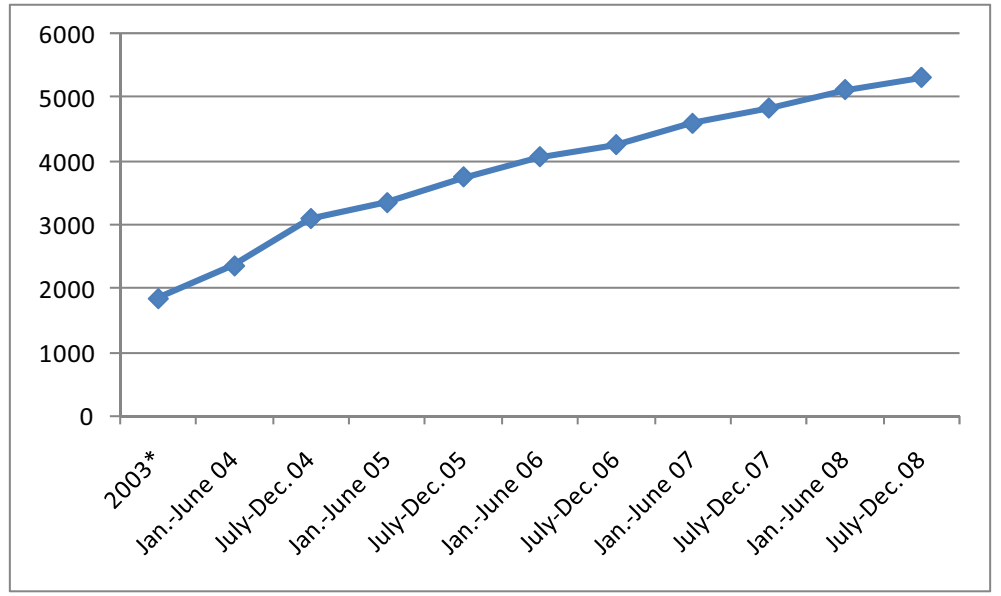

Fig. 1 Total number of volunteers

participated in Strong Families-sponsored activities and events. About one-third of these activities occurred in churches and another third in community centers, but a significant number were also held in schools $(9.0 \%)$ and libraries $(7.7 \%)$.

\section{Outcome Evaluation}

The outcome evaluation included data from a neighborhood survey and secondary analysis of ICD-9-coded child injuries, child protection services, and school survey data. For each data source, information was gathered from the Strong Communities service area and a matched comparison area. (For details of the outcome evaluation, see McDonell et al. (2015)).

The neighborhood survey involved interviewing a parent or caregiver of a child younger than 10 years in randomly selected households. The survey was administered

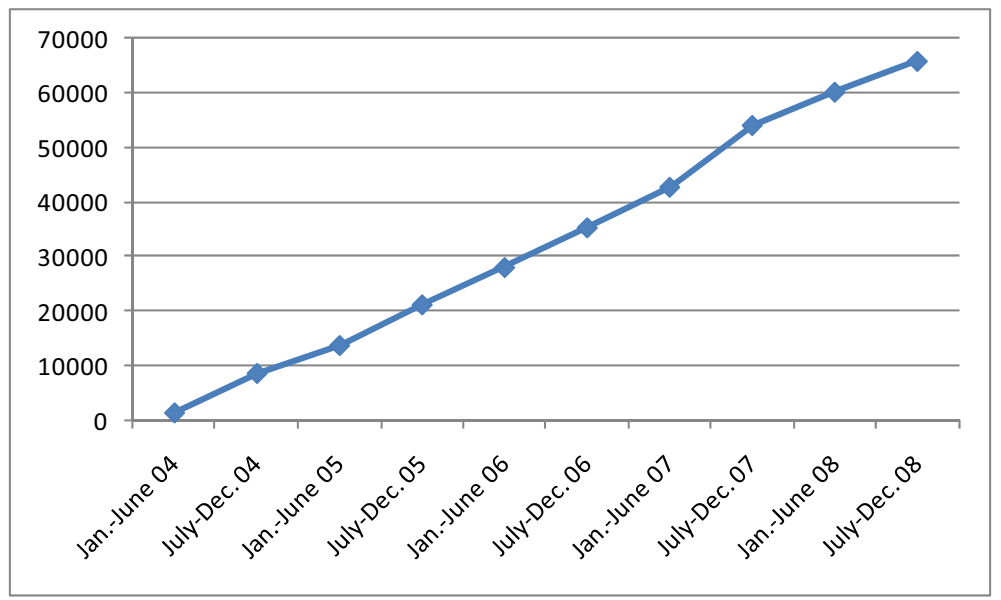

Fig. 2 Total number of volunteer hours 
Table 1 Volunteer activity and retention

\begin{tabular}{lccc}
\hline & Mean number of activities & Mean time spent per activity (min.) & Mean months retained \\
\hline Jan.-June 2005 & 3.8 & 13.8 & 6.9 \\
July-Dec. 2005 & 3.9 & 19.2 & 6.7 \\
Jan.-June 2006 & 5.4 & 29.2 & 8.7 \\
July-Dec. 2006 & 14.2 & 43.9 & 12.4 \\
Jan.-June 2007 & 26.2 & 40.7 & 11.4 \\
July-Dec. 2007 & 34.4 & 62.2 & 17.5 \\
Jan--June 2008 & 44.5 & 49.9 & 15.3 \\
July-Dec. 2008 & 59.3 & 70.4 & 19.1 \\
\hline
\end{tabular}

orally in the respondents' homes and lasted approximately $1.5 \mathrm{hr}$. Analysis of data from 2004 to 2007 showed that, across time and relative to matched communities, parents in the Strong Communities service area reported less parental stress, greater social support, more frequent help from others, greater sense of community and personal efficacy, more frequent positive parental behavior, more frequent use of household safety devices, less frequent disengaged parenting, less frequent neglect, and a trend toward less frequent assaultive behavior.

According to the child injury data, emergency room visits and inpatient stays attributable to neglect declined by $68 \%$ among children of all ages in the service area but by only $19 \%$ in the comparison area. All admissions for injuries resulting from maltreatment of children aged 2 and under declined by $23 \%$ in the service area but only $6 \%$ in the comparison area. Finally, all admissions for injuries resulting from maltreatment of children aged 4 and under in the service area declined by $38 \%$ but only $13 \%$ in the comparison area.

Analysis of CPS data showed that founded cases of child maltreatment among children aged 2 years and under declined by $11 \%$ in the service area but increased by $85 \%$ in the comparison area. Founded maltreatment decreased by $41 \%$ in the service area but increased by $49 \%$ in the comparison area for children aged 4 years and under. The rate of founded CPS cases among 3- and 4-year-olds remained constant in the service area and doubled in the comparison area. For children 9 years and under, founded maltreatment decreased by $8 \%$ in the service area but increased by $30 \%$ in the comparison area.

Finally, members of the Strong Communities research team used surveys developed by the South Carolina Education Oversight Committee related to the perceptions of parents, teachers, and students in an effort to both better understand their perceptions about the level of engagement of parents in schools and their perceptions about safety (Ben-Arieh et al. 2009). The research team analyzed information on home-school relations and children's safety from the survey of 5th graders. They found significant increases in beliefs of parents, teachers, and especially children that children are safe at or in transit to school and that parents are taken seriously by school personnel. Such beliefs became less common in matched comparison schools. 


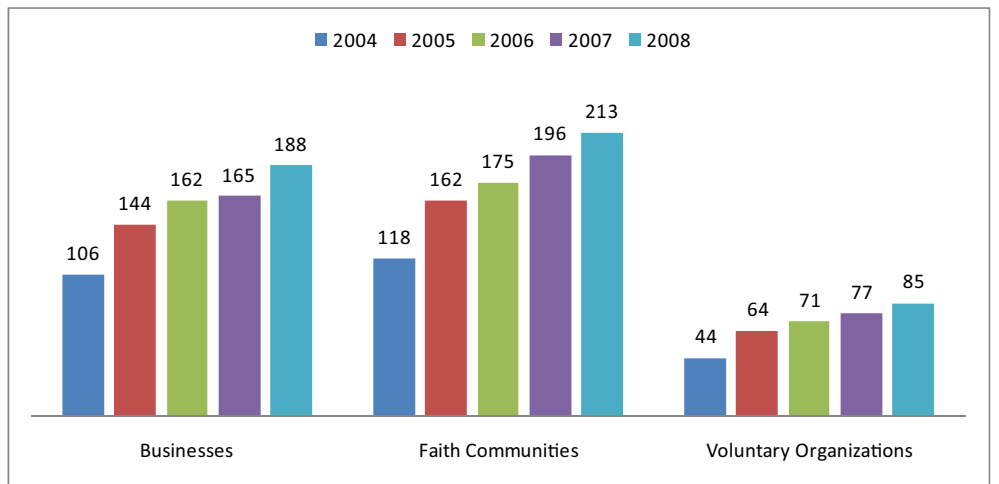

Fig. 3 Organizational involvement

\section{Achievements}

\section{Key Findings}

In 1993, the U.S. Advisory Board recommended re-focusing child maltreatment efforts toward prevention. The implementation of Strong Communities in South Carolina was the first attempt to actualize this neighborhood-based child protection strategy. During its 7+ years of implementation and through an extensive multi-method, multi-level evaluation, Strong Communities in South Carolina added substantially to the knowledge base on the role of community factors in children's safety. It also advanced understanding of how to operationalize some of the theoretical concepts undergirding the Board's recommendation (e.g., Kimbrough-Melton and Melton 2015).

Indeed, the Strong Communities effort in South Carolina showed that it is possible - even in the current age of alienation - to enlist communities in care for children and support for the children's parents and to sustain and deepen that involvement across several years. Mobilization occurred in diverse communities, with the greatest success (probably contrary to the expectations of most people) occurring in the most disadvantaged communities (McLeigh et al. 2015).

Volunteers not only engaged in the initiative, but they were able to explain the goals and the mission of Strong Communities, so that they themselves could "spread the word" (Haski-Leventhal et al. 2008). Hence, the volunteers were not merely "doing their activity" (e.g., participating in a neighborhood clean-up; helping with a Parents' Night Out). They also knew its purpose, and they supported the cause. Volunteers reported a desire to do whatever it would take to fulfill the goal of the initiative, and many played multiple roles in helping to achieve it.

Many volunteers helped to carry the Strong Communities message to the organizations with which they were involved and to engage those organizations in parent support. For example, one volunteer learned about Strong Communities through a presentation made at her Rotary club, but her involvement in the initiative extended beyond the club. She took the Strong Communities message to her church, which became involved in many efforts to support families, both in the church (e.g., forming a grandparents raising grandchildren support group) and in the wider community (e.g., hosting regularly scheduled parent-child activities; participating in a mentoring children 
of prisoners program). This exceptional volunteer also engaged the community where she lived and the community college from which she had retired as a professional staff member. Accordingly, she played an important role in the development of Strong Communities in four communities from one end of the service area to the other. As this example illustrates, community institutions are important means of reaching individuals in building norms of neighborliness, but participants in such settings also are important in shaping community institutions to be assets for families.

Indeed, the Strong Communities' experience proved to be transformative for both volunteers (Hashima and Melton 2008; Haski-Leventhal et al. 2008) and communities (McDonell et al. 2015). The evaluation studies showed that Strong Communities built a sense of community, created supports for families with young children, and helped to reduce child maltreatment within the service area.

Both the goal and the theory of Strong Communities were communicated on bumper stickers ("Strong Communities Keep Kids Safe") and other handouts and giveaway items. Moreover, they were elaborated in city council resolutions and proclaimed on signs at city entrances (e.g., "Simpsonville Is a Strong Community for Children") and apartment offices. The intent to prevent child maltreatment was forthrightly stated, and it was easy to elicit support across constituencies of diverse backgrounds, politics, and theology. It was not difficult to attain consensus in relation to community responsibility. However, the penultimate goal - ensuring that every child and parent know that when they have reason to celebrate, worry, or grieve, someone will notice, and someone will care - resonated at least as easily across communities and provided a non-stigmatizing basis for both engagement and planning. Furthermore, it was not difficult to persuade diverse groups that the penultimate goal of Strong Communities was indeed a corollary to the ultimate goal.

It is likely that collective action to build norms of neighborliness will go far toward preventing and ameliorating not only child maltreatment but also other social and health problems and, in general, improving quality of life. Communities' serious attention to the moral imperative to fulfill the right to personal security of all children is likely to make them better places to live for everyone and, in particular, better places for children to grow up. Seemingly "natural" enthusiasm for fulfillment of norms of neighborliness does create a sense that "People shouldn't have to ask!" and that even in hard times "People don't have to ask!" to obtain help in caring communities.

The demonstrated effectiveness of Strong Communities in enhancing schools' openness to parents - and probably thereby not only improving children's safety but also increasing children's own and their parents' engagement in academic programsis illustrative (cf. Limber and Kowalski 2020). Moreover, the foundation laid through such efforts may strengthen positive social networks and community identity more broadly by enhancing schools' position as centers of community.

\section{Noteworthy Lessons}

In that regard, there are three positive results of our work in Strong Communities that are especially remarkable. First, as one of us (Melton 2009) concluded in the title of the first book chapter summarizing studies of Strong Communities, "Strong Communities Restored My Faith in Humanity: Children Can Live in Safety." The point of the title was the continuing possibility of effective community-wide action to fulfill children's 
right to personal security, despite concerns about loss of community not only in the USA but also in many other countries across the globe (see Melton 1993, probing whether there is a place for children in the new world order, a question with profound but changing significance in the current context):

We in Strong Communities] have learned, to our great pleasure, that we can create situations in which whole communities can be enabled to help and be helped to protect and preserve children's personal security, parents' and other caregivers' efficacy, and families' integrity and well-being. Furthermore, communities can engage in such mutual assistance without being either demeaning or demeaned. The dignity of both children and parents can be protected, as community is both achieved and called upon. (Melton 2009, p. 84)

Consider by contrast the context in the early 1990s, when the U.S. Advisory Board was deliberating about their proposal for a national strategy in child protection. The Board not only had concluded that the crisis in child protection had reached emergency proportions (U.S. Advisory Board 1990), but it also had become aware of evidence suggesting that help was rapidly becoming - perhaps already had become - a commodity that Americans buy, not what they do (Melton 1992)! Note that these discussions presaged Putnam's (1995) landmark essay and (2000) encyclopedic treatise on the decline of social capital in American life, a trend that extensive empirical evidence shows had already been in place for a generation and that has escalated in the generation since the Board was developing its proposal (see, e.g., Davis and Parker 2019; Twenge et al. 2014).

Most vividly, however, the Board met just three weeks after the riots by many thousands of protestors in South Central Los Angeles in April-May 1992 in response to a jury's acquittal of police officers charged with using excessive force against an African American suspect apprehended after a high-speed chase ("1992 Los Angeles Riots," 2020; Sastry and Bates 2017). ${ }^{2}$ After a week, scores had been killed, thousands injured, and more than 12,000 arrested. Although the South Central Los Angeles riots did not directly relate to child protection policy and practice, they appeared to constitute a powerful indicator of the questionable feasibility of a neighborhood-based strategy in neighborhoods amid long-term decline, great need, and enormous distrust. Although the Board ultimately concluded that such a strategy still had the best chance of ensuring children's safety, the members sounded a warning ${ }^{3}$ :

\footnotetext{
${ }^{2}$ Coincidentally, the chair of the Board at the time of the release of the proposed national strategy (U.S. Advisory Board 1993) was the member from southern California (DeAnne Tilton Durfee, then and now the executive director of the Los Angeles County Inter-Agency Council on Child Abuse and Neglect).

3 The 15 members of the Board were appointed by the secretary of health and human services. For example, Melton was appointed initially during the second Reagan administration and then reappointed during the G. H. W Bush administration. Two of the seats were reserved for federal employees (typically relatively low-level presidential appointees; e.g., deputy assistant secretary of health and human services. The other 13 slots were focused on child protection constituencies (e.g., parent self-help organizations; state and local government; organizations providing services to people with disabilities) or professional disciplines (e.g., law; social services; teachers). Melton was appointed to the psychology seat.

Most of the public members' political affiliations were not obvious. In the few instances of a clear history of advocacy for the party of the appointing Administration, the relevant members uniformly did not act in partisan terms. Hence, most decisions were unanimous, including support for the language and recommendations of the Board's proposal for a new national strategy (U.S. Advisory Board 1993).
} 
The unfortunate irony.... is that the neighborhoods in most need may have the most difficulty in implementing a neighborhood-based child protection system. The Board believes that this problem usually is tractable, but that the reversal of negative social momentum requires diligent efforts to inject resources and to facilitate the development of neighborhood leadership....The safety of children should not be a function of geography; children in declining neighborhoods are just as entitled to protection as are their peers in neighborhoods with more resources. (U.S. Advisory Board 1993, p. 22)

Recognizing the seriousness and the difficulty of this issue, the Board called in its Recommendation 1 for action by the federal government and private foundations to "establish a large-scale demonstration program of Prevention Zones-comprehensive efforts to improve the social and physical environments in declining neighborhoods with high rates of child maltreatment" (U.S. Advisory Board 1993, p. 23). ${ }^{4}$ The Board called for such programs to occur in communities of diverse geography, population density, and ethnicity and to be "closely monitored and rigorously evaluated" prior to application "with such modification as suggested by evaluation studies...[in] a largescale national effort within five years" (p. 23).

Although the urgency and difficulty of addressing child maltreatment in neighborhoods in decline was given first priority, the Board also made clear in the commentary leading to Recommendation 1 that it envisioned that the neighborhood-based approach ultimately would be available for children throughout the society. Indeed, concern for the safety of all children and corollary responsibilities of all sectors of society permeated the report as a whole.

Of course, a universal approach is also likely to be especially effective in assurances (a) that families' needs will be addressed at the times and places that they are experienced and (b) that services will be acceptable and non-stigmatizing as parts of "natural" interactions. Although the trend is toward universally accessible formal prevention services (see, e.g., "Universal Approaches to Promoting Healthy Development," 2019), "Strong Communities remains distinctive among interventions for prevention of child maltreatment (see Molnar et al. 2016) in its being not only universal but also comprehensive and primarily reliant on informal assistance and integrated services (e.g., integration of family support into conventional pediatric health services and family recreation).

In the conviction that the effectiveness of efforts to protect children is dependent on such efforts being embedded in everyday life, Strong Communities uniquely applied the U.S. Advisory Board's (1993) vision. Indeed, the Board's challenge in the last sentence of the report was to "all American adults to resolve to be good neighbors-to know, watch, and support their neighbor's children and to offer help when needed to their neighbors' families" (p. 82, emphasis in the original). Accordingly, the Board

\footnotetext{
${ }^{4}$ This recommendation served as the foundation for a recent award-winning disruption paper (Roygardner et al. 2020) in a competition sponsored by The National Foundation to End Child Abuse and Neglect (EndCAN). A disruption paper is intended to disrupt conventional thinking, in this instance about prevention of child maltreatment.

${ }^{5}$ E.g., Family Connects offers an assessment leading to referral of families of newborns to formal services through community agencies (Haskins et al. 2019).
} 
understood the task of child protection to be no less than the transformation of the culture:

...The Nation must strive diligently to overcome the isolation created by the demands of modern life and exacerbated by the ravages of poverty. We must tear down the walls that divide us by race, class, and age, and we must create caring communities that support the families and shelter the children within them. We must take the time to see the need and to lend a hand. (U.S. Advisory Board 1993, p. 84)

The good news from Strong Communities is that, without tangible incentives, this message can draw the attention and the sustained collaborative action of a broad cross section of the community. For example, the theology and sociology of churches within a few blocks of each other in one community in the service area were sufficiently disparate that some of the professional staff members had never met. However, they came together both to spread the Strong Communities message (for example, in joint Blue Ribbon Sabbath observances) and to organize enhanced support for families of young children, both inside and outside the participating congregations. (For a lengthy list of church activities, many of them collaborative, see Melton and Anderson (2008, p. 180)).

Second, the even better news is that one person can change a community-provided that such an individual skillfully and diligently works to engage the community in adopting or strengthening norms of neighborliness (McLeigh et al. 2020). Together, the outreach workers directly or indirectly (with assistance of exceptional volunteers and organization leaders) recruited hundreds of organizations and thousands of volunteers to facilitate noticing and caring for young children and their parents.

In so doing, they accomplished the formidable challenge of normative (cultural) change in the participating communities. Surveys of random samples of community residents - most of whom it is unlikely that outreach workers themselves had ever met - showed changes in 'parents' care for their children and neighbors' support for one another, so that younger children are safer at home and in the community" (McDonell et al. 2015, p. 79). The import of these changes was manifest in official statistics in relation to children's safety (i.e., substantiated reports to CPS and injuries diagnosed in emergency department visits and inpatient stays (McDonell et al. 2015). Changes in help for one another-presumably, therefore in informal social and material support-were particularly pronounced in low-resource neighborhoods (McLeigh et al. 2015). Moreover, the level of activity in the Strong Communities initiative, again particularly in low-resource neighborhoods - could itself be viewed as a culture change. Parents and others had many opportunities not only to be engaged themselves but also to see others reaching out to families of young children - building expectations of care for one another and strengthening beliefs in their capacity to make a difference for their own and their neighbors' children.

Third, still more good news is that the most important resources needed to ensure children's personal security are usually already present, even in high-need communities. Indeed, Strong Communities works best when it capitalizes not only on the assets present (the existing human resources, social networks, and physical facilities; see Principle 10 in Kimbrough-Melton and Melton 2015, and McLeigh et al. 2020) but also on their strongest attributes. Thus, for example, the prevailing process in "evidence- 
based" human services is comprised of "manualizing" programmatic innovations and then insisting on fidelity to the stated strategic steps in implementation and evaluation. The manual for Strong Communities, however, is not a cookbook but instead a guidebook of principles. When some outreach workers struggled early in the initiative, we learned through trial and error that their successes grew faster, deeper, and more broadly when they started with settings and activities where they were sufficiently comfortable to generate their own tasks and to identify networks for action consistent with Strong Communities' principles and goals. Analogously, parents and volunteers engaged more quickly and creatively when they were invited initially to participate in Strong Communities activities in settings and networks already familiar and often already admired.

This approach naturally "snowballs" both networks and organizations into a community-wide effort. Moreover, it not only capitalizes on existing facilities (thus dramatically reducing fundraising required for property acquisition and/or maintenance), but it also promotes transformation of existing and potential centers of community. For example, early in the initiative, a small business owner who was participating in a community work group volunteered to donate use of a building on his property to become a toy library named after his grandmother. The volunteer also contributed funds for basic remodeling (e.g., addition of a toilet) consistent with the new purpose. The working group enlisted Scouts to staff the library, and the volunteer panel also began to establish a program of activities to bring families together (e.g., weekly movie nights).

Predisposing community cohesion in support of Strong Communities is that the approach calls upon values that are at once culturally consonant and broadly humanistic. Strong Communities both restores and strengthens long-standing American norms of volunteerism (see, e.g., Levine 2013; Toqueville 2004) —in effect, individual responsibility expressed through collective action, commonly through clubs, congregations, and other voluntary associations, including informal discussions and neighborly service. Although such commitment has been in decline for approximately a halfcentury (see, e.g., Bellah et al. 2008; Putnam 2000), volunteerism remains a value that has been deeply embedded in American culture for centuries, in part as a corollary to Protestant religious pluralism (Toqueville 2004).

In that regard, neighborly service to children ("the least of these") and their families, particularly those who are on or outside the margins of the community, is fundamental to the great religious traditions (Melton 2010, 2014; Pohl 2011). Consequently, notwithstanding the peculiarly or at least unusually American aspects of grassroots organizing for family support, we have found easy acceptance of the ideas that Strong Communities represents among people of widely diverse nationalities and religions. ${ }^{6}$ Accordingly, our

\footnotetext{
${ }^{6}$ Given both the international focus of the Clemson University graduate program in International Family and Community Studies and the multi-national origins and current homes of its students and adjunct faculty, Strong Communities in South Carolina had numerous participants and visitors from abroad. An article discussing Strong Communities from these disparate perspectives is currently being prepared by authors originally from Belarus (predominantly Orthodox), the Dominican Republic (Catholic), Israel (Jewish), Kosovo (Muslim), New Zealand (Protestant), the USA (Protestant), and Uzbekistan (Muslim) - countries that are widely diverse in both religion and the strength of democratic political traditions. Other international visitors to Strong Communities came from Albania, Australia, Canada, the Czech Republic, the Dominican Republic, Estonia, and India. Students (now graduates) participating in the initiative who are not among the authors of the article in preparation are citizens of - or immigrants or children of immigrants from - Canada, China, the Czech Republic, Kosovo, Lithuania, Russia, Saint Lucia, Uganda, the United Arab Emirates, and the USA.
} 
colleagues in Tel Aviv and their students and associates have been pleasantly surprisedactually stunned - by the success that Arab students have had in recruiting Jewish families for participation in Strong Communities. Given the relative lack of community organizations in Israel, student outreach workers knocked on doors of families, not of organizations, to introduce them to Strong Communities:

This strategy has proven to be beneficial on multiple levels. The students had expected to have relatively short conversations with families, but several of them spent hours talking with the families about their parenting challenges and thoughts on the neighborhood. Also, the Israeli Arab students had been nervous about the door-to-door strategy because of the religious makeup of the community [mostly Jewish but with diversity in the degree of religiosity, from secular to ultra-Orthodox]. The hospitality of the residents, however, amazed all of the students. In fact, 2 weeks into the effort, the students who had been the most successful in engaging families were the Arab students. This success created a great deal of excitement among the students and increased their confidence. (McLeigh et al. 2017, p. 401)

The bridging of racial, ethnic (national-origin), political, theological, age, and gender differences in Strong Communities in South Carolina was obviously similar in its significance. Such mastery of historically disabling differences in Israel and the American South, although of relatively small scale, in the service of a broad-based community of concern for children and their families may reflect the near-unanimity of acceptance of children's rights and the unparalleled breadth of their recognized scope (Convention on the Rights of the Child 1989). ${ }^{7}$ Thus, with its goal of fulfillment of children's right to personal security, Strong Communities may provide corrective experiences useful in overcoming group differences among people in other age groups and on topics of less fundamental importance.

\section{Challenges}

Just as we have noted three remarkably positive impressions left by our experience in Strong Communities, we have noted three major challenges. First, despite communities' widespread readiness for an initiative to build and strengthen relationships and, by so doing, to make parents' lives easier and their children's lives happier and more secure, achievement of a culture change is hard work! A common summary by staff and volunteer leaders is that Strong Communities is not a job; it's a way of life! Much like other professionals who are community convenors (e.g., clergy; elected officials), outreach workers need to be available when and where the people are. The nature of the work, the interests and values of the people who are recruited to do it, and their level of motivation also imply that there is not a clear boundary between work and home life. The opportunities that one seeks to find and fulfill for the community and those that one seeks to find and fulfill for one's family are commonly the same.

\footnotetext{
${ }^{7}$ Every country has signed the Convention on the Rights of the Child (1989), and all but the USA have ratified it, thus recognizing the treaty in their domestic law. No other human rights treaty approaches the Convention in its breadth and depth.
} 
Moreover, to build new community norms, the message must be repeated as often as possible, as many ways as possible, in as many settings as possible. ${ }^{8}$ Consistent with the general injunction to "push the envelope" (Principle 3 in Kimbrough-Melton and Melton 2015, and McLeigh et al. 2020), staff were encouraged to be continually starting or facilitating initiation of projects consistent with the desired community transformation (hence, closely linked to the primary goal of "keeping kids safe" and the penultimate goal of ensuring that children and parents are noticed and cared for (Principle 1).

As one early leader in the initiative noted, the job of an outreach worker or an exceptional volunteer is never finished. As the work progresses, its leadership becomes more and more diffuse. Volunteers assume more responsibilities, and their activities become more highly integrated into the community organizations of which they are a part. However, there are more and more volunteers from more and more organizations, and their activities increase in complexity, diversity, and frequency.

A vivid documentation of this process occurred when the Clemson institute's public information director, a professional journalist, would interview outreach staff, usually every two weeks, about their checklist-style reports of contacts and activities. Brief, almost bullet-style stories about these projects would be printed on single-spaced paper, and they were then collated in 3-inch notebooks. ${ }^{9}$ When visitors came to "see" Strong Communities in action, the initiative director (Melton) was often asked to describe how the guiding principles translated into action. His standard response was to ask the visitor to pick a month during the implementation. He then pulled the pertinent volume from his bookcase and handed the relevant printout to the guest to skim. What quickly became obvious was (a) that the activities did in fact conform to the principles and (b) that hundreds of such projects would be underway at any point in time.

This anecdote (actually, this set of anecdotes) implicitly illustrates the enormity of an intervention designed to change community culture and its complexity when the particular goal is to ensure children's personal security. It also gives a glimpse of the difficulty and expense involved simply in chronicling such an effort, even in a relatively small geographic area in which the total population of interest is barely into six figures. Note in that context the wisdom and the large cost of the U.S. Advisory Board on Child Abuse and Neglect (1993) Recommendation 1 for expedited implementation and evaluation of its proposed strategy in multiple Prevention Zones. Imagine, e.g., random assignment of numerous communities to participate in Strong Communities with various substantive emphases and regional differences. Multiply those difficulties with consideration of the substantial methodological problems in measuring not only child maltreatment itself but also the activities involved and the

\footnotetext{
${ }^{8}$ See, e.g., Principles 3, 2, 4, 5, 9, 8, 7, and 6, respectively, in Kimbrough-Melton and Melton (2015) and McLeigh et al. (this issue), exhorting staff continually to "push the envelope" to create new structures and processes, recruit and nurture volunteers, strengthen relationships among families and with community institutions (especially networks for mutual assistance), enable parent leadership and community engagement, and assist parents to increase material and social support for families with young children.

9 These "biweeklies" and the time-and-motion data on which they were based formed the heart of the initiative's process evaluation (Berman 2020; Berman, Murphy-Berman, \& Melton, 2008).
} 
intermediate outcomes (see, e.g., Christ and Schwab-Reese 2020; Committee on Child Maltreatment Research, Policy, and Practice for the Next Decade, Phase 2 2014; McDonell and Melton 2008). It is clear that discrete evaluation of particular strategies is neither feasible nor desirable; the questions are the nature and effectiveness of the culture change (in effect, the "big picture" in relation to children's personal security).

Second, prevention is still a tough sale, at least in regard to child protection. Although some human service professionals indicate skepticism that volunteers can provide meaningful assistance to families in great need, ${ }^{10}$ the typical reaction to the story of Strong Communities is one of enthusiasm, almost always from the general public (regardless of sector) and usually from professionals in the field. As we noted supra, the values embedded in Strong Communities are both culturally congruent in the USA and humanistic in a global context. With the emptiness that comes with generations of decline in social capital, there is an excitement that comes with (re-)discovery of the power of mutual assistance in the context of a shared sense of community. Strong Communities makes (re-)creation of such networks seem like a natural rhythm of community life.

As one would reasonably assume from that response, it is not difficult to elicit interest in implementing Strong Communities. However, it is surprisingly difficult to achieve adoption and, if so, to obtain effective leadership necessary for full implementation. There are several obstacles in our experience.

Probably the biggest obstacle is the first challenge that we noted: achievement of a culture change is possible, but it is hard work. Administrators and line staff may decide that there is not enough energy within the organization or centrality in its mission to warrant the level of volunteer activity and organizational change required.

An organization (or a federation of organizations) may in fact be able to re-cast or strengthen existing assets or programs (e.g., a university's service-learning classes and/or student service organizations) in a manner consistent with Strong Communities principles. However, doing so requires an organizational commitment with designation of a visionary leader who understands and embraces the goals and principles (much like the exceptional volunteers and outreach workers in the South Carolina initiative; see Hashima and Melton 2008, and McLeigh et al. 2020) and who has a job description that provides the time and authority to enlist others in a Strong Communities initiative.

It would also be helpful for the leader to be known in the community and to be experienced in building alliances with community groups. It does not matter whether the leader is a current employee whose position is re-defined (e.g., a

\footnotetext{
$\overline{10}$ This perspective is based in part on inferences drawn from unrepresentative behavior samples. Office-based, professionalized practice shows clients at their most disadvantaged, least competent - one of the lessons that Strong Communities in Israel has taught supervising social workers (Katz et al. 2019).

Skepticism about reciprocal community engagement also emanates from common errors in social perception that may become entangled in clinicians' operating theories:

Like the general public, mental health professionals are prone to make the fundamental attribution error- to overlook statistically powerful situational factors and instead to assume, typically incorrectly, that behavior is primarily the product of individual motivation. The big although oft-disregarded message of contemporary social science is that situations typically matter much more than do personal traits. (Melton 2013, p. 6; see Ross 1977, for articulation of the fundamental attribution error)
} 
community psychologist or social worker who assumes the campus leadership of Strong Communities as a part of the faculty member's job description, perhaps at the professor's own initiative), a current employee whose job description is already compatible (e.g., an associate provost or associate dean with lead responsibility for community engagement), or an individual specifically recruited to lead Strong Communities.

Cost is often perceived to be an obstacle. However, it is typically not a problem that is as formidable as it appears to be. Although we were fortunate to have long-term, large-scale funding from The Duke Endowment, a large proportion of that funding was for development and evaluation expenses. The cost-effectiveness of Strong Communities is exceptional, given the community-wide effects, the limited personnel cost (in South Carolina, one outreach worker to approximately every 20,000 residents), ${ }^{11}$ and the staggering costs, both tangible and intangible, when child maltreatment does occur - by a team of CDC researchers' estimate of the total costs of child maltreatment in the USA, trillions of dollars each year! ${ }^{12}$

Moreover, as discussed infra, we believe that core expenses for a Strong Communities initiative can often be covered through conventional revenue streams and redirected expenses. We suspect that the failure to do so reflects a belief that prevention, especially when not limited to communities or families in great need, is a lowpriority endeavor. This perspective is common even though (a) Strong Communities is a universal approach and therefore includes efforts to mitigate effects of maltreatment ${ }^{13}$ and (b) that such an approach diminishes stigma and enhances access to community resources.

Third, the coronavirus pandemic may be a long-term threat to community. In that regard, in the first weeks in which the coronavirus pandemic became evident in the USA, reports of suspected child maltreatment decreased (relative to either the month preceding school closing or the same month in the preceding year) by dramatic and roughly comparable levels across the USA; e.g., about one-third in Los Angeles County (Venkatraman 2020), Connecticut (Dignan 2020), and Maine (Stout 2020); about one-half or more in Louisiana ("Suffering in silence" Worries mount over drop in reported child abuse cases 2020), Massachusetts (Stout 2020), ${ }^{14}$ the Twin Cities (approximately 45\% in Hennepin County (Minneapolis), MN, and 65\% in Ramsey County (Saint Paul), MN; see Horner 2020), Montana ("Suffering in silence" Worries mount over drop in reported child abuse cases 2020), New Hampshire (Stout 2020),

\footnotetext{
${ }^{11}$ Depending on the size of the initiative, there may of course be other personnel expenses that are spread across the outreach areas (e.g., a director; a public information coordinator; an evaluation coordinator; an office manager). There may also be modest operating expenses (e.g., funds for community luncheons, dinners, or fun days). However, such costs often can be covered by donations.

12 Researchers at the Centers for Disease Control and Prevention (Peterson et al. 2018) have estimated that the per-victim lifetime cost in the USA in 2015 USD of non-fatal child maltreatment was $\$ 830,928$ and of fatal child maltreatment was $\$ 16,615,186$. Among the costs considered were pain, suffering, and grief and costs incurred by health care, child welfare, criminal justice, and special education systems. The aggregated costs are truly stunning: for substantiated non-fatal child maltreatment, $\$ 428$ billion; for investigated non-fatal child maltreatment, $\$ 2.0$ trillion; for fatal child maltreatment, $\$ 27.8$ billion.

${ }^{13}$ It is true, however, that Strong Communities' method and goals are forward-looking (e.g., "Strong Communities keep kids safe!") and, therefore, oriented toward prevention. The principal goal is to reduce threats to children's personal security.

14 This trend has not been limited to the Boston area, which has been a hotspot for the coronavirus. E.g., referrals to the child advocacy center in Bristol County, MA, declined by about two-thirds (Loranger 2020).
} 
Oklahoma ("Suffering in silence" Worries mount over drop in reported child abuse cases 2020), Pennsylvania (Couloumbis 2020), and Washington ("Suffering in silence" Worries mount over drop in reported child abuse cases 2020).

Anecdotally, some child protection program directors reported that the decrease in abuse cases was accompanied by an increase in the severity of the reports that were brought to authorities (Blanks 2020; Schmidt and Natanson 2020). Moreover, Childhelp's national child abuse hotline (a resource more likely to be used by nonprofessionals seeking help informally) reported an increase in the frequency of calls of about one-fourth and of texts of more than 250\% (Venkatraman 2020).

Expressing concern about the potential for a "child abuse epidemic" as a byproduct of the coronavirus epidemic, Agrawai (2020) wrote an op-ed in the New York Times in which she called on neighbors and community professionals (e.g., clergy; organizers) to substitute during school closure for "the watchful eyes of teachers, guidance counselors and day care providers [who] serve as lifelines for vulnerable children." A pediatrician specialized in child protection at Columbia University, Agrawai further encouraged "people who are concerned about a particular family can help by doing small things to ease the stress that comes with this time"-or, we'd argue, "ordinary" times. Such "small acts of support" might include "food, toilet paper, coloring books or just an empathetic ear"- perhaps most importantly, service "as a reassuring, reliable presence" (in effect, a dependable friend!).

Underlying Agrawai's concern and the plethora of newspaper stories about the "bad news" of a dramatic, apparently national decline in reports of child maltreatment are three assumptions. First, there is worry that the actual prevalence of maltreatment is and will be on the rise during the pandemic, because of (a) many families' loss of income and, therefore, their inability to provide adequate nutrition, health care, etc., (b) a resulting spike in both acute and chronic stress in relation to both practical matters and health itself, (c) increased family conflict and decreased family pleasures as a result of sequestering, (d) substantially reduced access to social support and other resources, and (e) a lack of external scrutiny of both family process and child well-being and therefore a reduction of informal social control deterring abusive and neglectful practices. Second, with families "hunkered down" because of state stay-at-home orders and corollary school, workplace, and child-care closures, there is worry that maltreatment will often go undiscovered and therefore unreported. Third, there is worry that, absent referrals to public authorities with ordinary investigations (including home visits, notwithstanding instructions for social distancing) to follow, abused and neglected children will be left vulnerable without services needed to interrupt the maltreatment. In that context, some are particularly concerned about the reduction in referrals from professionals, whose reports are disproportionately substantiated and followed by services (JonsonReid et al. 2020).

To be clear, our own concern about the coronavirus-related precipitous decline in reporting of suspected child maltreatment is not anxiety about underreporting per se. Rather, our worry is about the breakdown in informal support and control that occur when community institutions are undermined or wither away. In a society in which affirmative, community-wide efforts were already needed to forestall social isolation associated with child maltreatment (see Thompson 2015), what happens when the new ostensibly prosocial norm is "social distancing"? What will happen, even after churches 
re-open, when families have become accustomed to their place of worship being shuttered? What will happen to the PTA, youth clubs, sports teams, and informal parent-teacher contacts? Will they be included in the "new normal" when the pandemic subsides, perhaps years after it began? When unemployment approaches depression levels, how will families make ends meet? What will happen when public agencies' and private charities' resources are depleted, and friends and relatives themselves are in great need?

Accordingly, it is a safe bet that there will be an extraordinary need for Strong Communities or something like it in the coming months and years to mobilize communities in support of children and their families. Loneliness - perhaps the greatest public health challenge of our era, both pre- and post-coronavirus (see Murthy 2020; Vedantam 2020) - has increased, and it is continuing to do so. ${ }^{15}$ Such unhappiness is occurring at a time of great challenge and plummeting resources. It is not at all clear, however, what modifications are needed to fit current and forthcoming realities. Zoom and other electronic media may be part of the answer. However, we are sure that opportunities for online communication will not by themselves offer either the tangible or intangible support needed to ensure children's personal security.

\section{What's Next?}

\section{Expanding Opportunities for Strong Communities}

We have long argued that the next steps for Strong Communities should be carefully evaluated large-scale replications in diverse contexts, just as the U.S. Advisory Board (1993, Recommendation 1) recommended more than a quarter-century ago. Our emphasis in that regard is based on the demonstration that has already occurred (a) that Strong Communities can result in a general improvement in families' quality of life and a specific improvement in children's personal security (McDonell et al. 2015; McLeigh et al. 2015) and (b) that the process of development varies in relation not only to national culture (McLeigh et al. 2017) but also to local assets and interests (Berman 2020; Berman et al., 2008; Murphy-Berman et al. 2008). In short, there is now more than ample reason to go to scale in community-wide efforts to enhance children's personal security through family support.

At the same time, the need to identify key strategies and problems in community mobilization and institutionalization of resources (in Strong Families) implies the

\footnotetext{
${ }^{15}$ Former U.S. Surgeon General Murthy (2020) has pointed out that the effect of loneliness on life expectancy is comparable with the consequences of smoking more than a half-pack of cigarettes per day. Indeed, there is greater reason for collective concern about public health action to prevent social isolation than either obesity or smoking.

Although the impetus was more in regard to the health consequences for older adults than for families with young children, the UK's unique ministerial portfolio for loneliness includes a plan to enable all National Health Service patients to have access to community activities and voluntary services as an antidote to loneliness (Prime Minister's Office 2018):

The practice, known as "social prescribing," will allow GPs to direct patients to community workers offering tailored support to help people improve their health and wellbeing....As part of the long-term plan for NHS, funding will be provided to connect patients to a variety of activities, such as cookery classes, walking clubs and art groups, reducing demand on the NHS and improving patients' quality of life.
} 
ability to compare efficiency and effectiveness in geographically and demographically diverse communities and in various sectors within them. For example, in the South Carolina initiative, the wealthiest, most organized communities (in this instance, suburban small towns) had the least outreach-worker coverage (in one instance, 1 to 50,000 residents), but they nonetheless showed the largest changes (all in the desired direction and relative to low-resource communities in the service area and both high- and low-resource comparison communities) in self-reported parenting practices (increased positive parenting, decreased disengaged and neglectful parenting, and decreased verbally and physically assaultive behavior; see McLeigh et al. 2015). The high-resource communities in the service area also had the greatest decrease in founded cases of physical abuse and the smallest increase in founded cases of neglect. However, improvement on intermediate variables, including indicators of community engagement, was greatest in the low-resource communities.

These results suggest that positive changes in children's safety can be obtained with less costly, labor-intensive strategies (e.g., more use of mass media) in communities that already are highly organized and that have easy access to formal services. In such an approach, outreach workers might act more as coordinators and facilitators and less as organizers and convenors. This hypothesis should be directly tested. The cost and administrative challenges would be formidable in implementing both the intervention and the evaluation in enough communities to vary the nature of outreach workers' strategies and to do so in a way that community characteristics can be co-varied. As a practical matter, sponsorship of such a large-scale initiative for normative change and related services research implies a substantial investment, probably within the capacity only of the federal government or a consortium of large foundations.

\section{Small-scale Locally Supported Development}

We also need strategies that are not grant- or appropriation-dependent and that can be undertaken and sustained on a smaller but still community- or county-level scale. It is not hard to imagine ways that existing resources could be re-configured to enable Strong Communities initiatives in particular towns, neighborhoods, or organizations, especially if training, consultation, and evaluation were available from another source (e.g., a center based in or supported by a foundation or a state government) and modest operational support was available from a local donor (most likely a local foundation, business, or philanthropist) to enable sponsorship of community events without additional fundraising.

The actual and potential examples of local initiatives that we describe here, at least hypothetically, are or would be based in a single sector but not limited to it or even "owned" by it. Instead, the organization of the Strong Communities initiative would be reliant on a particular community asset and the organizations within its informal network. The examples given here are based on the outreach of a university or a health clinic or system. Those examples were chosen because they have the potential to be self-funded through existing streams of revenue.

Less plausibly, we could also imagine a volunteer-led, single-sector-based initiative that became community-wide through the volunteers' personal 
connections. For example, the Parent-Teacher Association (PTA) for a school district might undertake a Strong Communities-initiative that begins to organize parents of school-age children through a strategy of mutual assistance, that relies on a combination of volunteers and school staff to build other family support, and that strives to strengthen norms of care for children and assistance to parents through PTA members' employers, neighborhood associations, civic clubs, and places of worship.

An analogous process could be imagined in other sectors in some communities. For example, an interfaith council might strive, beginning with member congregations, to mobilize the community, including secular organizations (e.g., schools; civic clubs) to protect children.

Similarly, a multi-sector but single-organization group (e.g., a United Way council; a community-development association) might sponsor a Strong Communities initiative. Having a venue for inter-sector communication does not usually do much by itself to generate community-wide collaborative action (see, e.g., Daro 2005).

\section{University-Based Initiatives}

By contrast, a university-based initiative may be able relatively easily to rely on students in service-learning classes or relevant student organizations (e.g., service clubs; religious organizations; pre-professional clubs) to act as outreach workers. (This is the model that has been used for Strong Communities activities in Israel.) Under this approach, the core funding is likely to come from tuition (or student-affairs funding, if a staff leader for student organizations is the principal leader of the effort). Time of other leaders or supervisors may be donated by cooperating community organizations, or there may be additional tuition-supported assignments of other faculty or graduate assistants.

The relevant courses could be practical in numerous disciplines (e.g., marketing; journalism) in addition to helping professions. They may also be service-learning components of classes on community development, child maltreatment, school-community relations, childhood, social movements, community nursing, and so on.

To make this model go, there are two critical ingredients in our experience. First, as we discussed supra, the campus leader must understand the underlying principles and their rationale, and she or he must embrace the approach and its possibilities. In that regard, the leader must also be committed to the goals of Strong Communities. She or he must believe in the collective responsibility to fulfill children's right to personal security and, like an outstanding outreach worker, "see" the pertinent assets in the university and the community at large and imagine how they might be integrated in build or strengthen norms of noticing and caring for young children and their parents.

In that regard, a university-based initiative has a range of assets that can be capitalized upon and that go well beyond the student volunteers and their professors and supervisors. For example, alumni can be key volunteers in supporting familiesand coaching students in their work in the community. Depending on the particular constellation of academic programs, they themselves and faculty (current and retired) may become partners in integrating Strong Communities into businesses, civic organizations, state and local government, health clinics, public safety agencies, religious 
organizations, schools, and other sectors of the community (all of the partners on which Clemson relied; see Berman, this issue).

Indeed, universities themselves are often major providers of health care, mental health services, recreation, youth programs, child care, business consultation, and arts programs. They are also typically major employers with staff at multiple levels. Hence, they are well-positioned to be models for community development and family support. They also have access to the expertise needed for program design, training, and evaluation.

Second, university-based initiatives must be designed with sensitivity to the limitations of the academic calendar. Otherwise, activities may be limited, as a practical matter, to February-April and September-November, with "loss" of summers and the beginning and ending weeks of the semesters. Also, the initiative may be locked into a mode of "déjà vu all over again," as each new cohort of students re-starts Strong Communities.

This foible can be overcome by strategic reliance on thoughtful community volunteers and year-round students (often graduate assistants), who may serve as historians, guides, and trainers. These longer-term participants may introduce new students to the community, and they also may bring students up-to-date about developments in the prior months and years. In the meantime, the lead instructor can educate new students in the rationale for Strong Communities and the principles for implementation.

\section{Strong Communities in Primary Health Care}

Another approach with which we have some experience for self-funded initiative is integration with community-based primary health care, whether it is grounded in community, family, or pediatric care - ideally with a link to community-based obstetric care. In this regard, we were inspired by our former colleague Francis Rushton, who is now retired but formerly was a community pediatrician in Beaufort, SC, and a member of the pediatrics faculty at the University of South Carolina. Rushton (1998; Rushton and Kraft 2013) has been a pioneer in using pediatric practice to strengthen informal social connections and thereby to reduce social morbidities, improve young children's health, and enhance their parents' effectiveness and well-being.

The cornerstone of Rushton and his colleagues' (Rushton and Kraft 2013) innovation has been use of group visits for well care for young children. Approximately eight families of children roughly the same age (or sharing some other common trait; e.g., enrollment in the same day care center) are scheduled together for well care; hence, for 90-120 min for eight families, not 15 min per family. Thus, although the service is at worst cost-neutral from the providers' perspective, it is an experience remarkably different for families accustomed to ordinary well care, usually with an immunization and a brief examination and conversation.

Typically, there are two providers per group (usually a pediatrician or family physician in collaboration with a nurse-practitioner or physician's assistant). One provider leads the group discussion (with enough time for the anticipatory guidance that is expected under American Academy of Pediatrics (AAP) guidelines), while the other administers examinations and immunizations and has private conversations as needed with individual parents. The group discussions not only enable education and mutual assistance, but they also provide opportunities for identification of common 
needs (matters for Strong Communities outreach to other organizations) and announcements about resources (e.g., family activities) currently available.

When used for Strong Communities, we encourage doubling the AAP-prescribed frequency of sessions; hence, e.g., one per month during the first year of life. We also encourage using the "extra" sessions specifically to enhance access to social support. For example, an Ask-the-Docs social event can strengthen mutual assistance, build relationships, and offer information, perhaps with opportunities for engagement and leadership in the broader community.

Apart from the direct reimbursements, ${ }^{16}$ there are other potential economic advantages to practices that make group visits part of their usual care. In localities in which enrollment of pediatric patients is competitive, the greater responsiveness, the increased attention, and the new opportunities for relationships and mutual assistance with parents in similar situations are likely to give practices using group visits an advantage in recruitment of young children and their families. It may also be possible to draw Medicaid administrative costs (50\% match) for work in facilitating families' access to services.

The integration of Strong Communities with group pediatric care has multiple advantages:

- With reimbursement for well-care visits and insurance (whether private or Medicaid) covering such costs for most children, well care is a potential framework for sustainable funding for Strong Communities.

- Notwithstanding the problems of access in American health care, almost all children receive at least some pediatric well care. It is a universal, largely nonstigmatizing system.

- Just as group prenatal care for parents-to-be does (Committee on Obstetric Practice 2018; Gold 2019), group pediatric well care provides parents with networks of friends with similar needs, at the same time that it greatly increases access to, and alliances with, their child's primary health care provider. It also enables much more use of visit time for education (anticipatory guidance), including information about ways of increasing children's safety and enhancing families' well-being.

- Although parents in general typically prefer group visits, effects on child well-being may be greatest for ethnic-minority parents, adolescent parents, military parents, parents with chronic health problems (e.g., diabetes), and others with special needs for education and support (Committee on Obstetric Practice 2018).

- In Rushton et al.'s (2015) quasi-experimental trial of Well Baby Plus (group well care in combination with home visits by a parent educator), children in $\mathrm{WB}+$ were almost twice as likely as matched comparison children receiving conventional care to complete all scheduled well-care visits, and they also were more likely to have obtained scheduled immunizations by 18 months. Parents in the WB+ condition remembered more of the anticipatory guidance about safety, toilet training, and discipline strategies, and their children were less likely to be obese. Parents

\footnotetext{
$\overline{16}$ The question that still remains to be resolved in relation to financing is third-party providers' willingness to increase the frequency of well-child visits. Given the documented positive effects on service efficiency (e.g., keeping appointments), family health practices, and child outcomes (e.g., obesity prevention) and the difficulties in cramming standard anticipatory guidance into 15-min sessions in which follow-up and immunizations must also occur, we are optimistic.
} 
receiving $\mathrm{WB}+$ also reported greater sense of efficacy as parents. In $\mathrm{WB}+$, there were also non-significant trends suggesting a diminution of use of the hospital emergency department and an increase in time out as a disciplinary strategy. In general, both the efficiency and quality of care are improved with group visits, whether used as the exclusive or partial method for pediatric well care (Coker et al. 2014).

- By integrating formal and informal support, a health-system-based Strong Communities initiative provides multiple bases for community-wide support for families with young children: "friendly" neighborhood-based health services; parent-toparent mutual assistance; volunteer support in community organizations; professional assistance in cooperating agencies (cf. Garg et al. 2015, providing for screening at infant well visits on problems in meeting families' basic needs (e.g., food security; child care; housing) and corresponding referrals to relevant agencies).

At least in ordinary times (outside the pandemic that is dominating practice at this writing), the biggest obstacles to adoption of the group model of well-child care are (a) that it is not conventional (hence, providers must be motivated to go beyond the comfort zone of their training) and (b) that clinics generally want to avoid financial risk (hence, they would prefer to avoid being the trailblazers, even for modest trials of an innovation requiring new or re-configured resources.) The logic and experience behind group services are sufficiently compelling, however, for practitioners interested in minimizing social morbidities, such as child maltreatment.

When there is agreement on moving forward, there are two common practical challenges in moving to a group model for pediatric well care. First, administrative staff may find group scheduling to be cumbersome. Second, few clinics have space available for meetings of multiple families with young children with adjacent space for private examinations, immunizations, and conversations.

Both challenges offer the opportunity of conversion of lemons to lemonade. Given the frequency with which Lamaze classes are held in obstetric practices, group therapy in psychiatry departments, nutrition classes in family clinics, and so forth, problems involved in group scheduling can easily be overcome if there is the administrative will to do so. The "Cadillac" response in this regard, however, is to assign or hire a coordinator of pediatric well care (or Strong Communities). Such a staff person might be a community nurse, a health educator, a medical social worker, or a patient advocate or navigator.

The coordinator's job is to facilitate well care and other Strong Communities activities inside the clinic while undertaking an outreach worker's tasks outside the clinic (perhaps 50\% each). Tasks might include the following:

- $\quad$ setting up group visits (including scheduling), ensuring that space and equipment are available, establishing the agenda, and sending reminders both to providers and to parents;

- co-leading group meetings;

- assisting with individual-family follow-up (e.g., referrals for social and economic assistance; monitoring resolution of clinical needs);

- leading group follow-up (e.g., addressing needs voiced by the group in relation to either clinic services or community resources and challenges); 
- meeting with leaders of community organizations (e.g., religious congregations; civic clubs; day care centers) about support that they might give (or in which they might collaborate) so that group members and other parents of young children might feel noticed and cared for;

- recruiting and coordinating volunteers for such efforts;

- sending weekly newsletters to parents with information about community resources and events for families and about care for, and health needs of, young children (for pertinent materials, see, e.g., HealthyChildren.org, a Web page for parents; produced by Bright Futures, the health promotion initiative of the American Academy of Pediatrics; see https://brightfutures.aap.org/Pages/default.aspx).

Thus, the relatively small administrative problem of group scheduling can serve as the impetus for expansion of clinic services to provide not only social assistance for group members but also clinic leadership across the community in outreach and advocacy consistent with Strong Communities goals and principles.

The lack of adequate meeting space within a clinic may also prove to be a blessing in disguise. The common answer is to identify a nearby facility that has a sufficiently large meeting space, that has an office or small meeting room that could be used for examinations, and that ideally already has space and equipment suitable for young children's play. For example, the group visit could take place in a child care center, elementary school, recreation center, library, or church.

Besides being a starting point for outreach, the change of venue may facilitate linkages to sources of services or enable collaboration with staff in another sector. In Rushton et al.'s (2015) Well Baby Plus, for example, group members shared a schoolemployed home visitor who was a parent educator in the Parents as Teachers program. The parent educator not only visited the homes of group members, but she also attended the group meetings and thus made connections between the group discussions and the home lessons. The school setting also provided a transition to classroom-based early childhood programs that would follow the home-based education in child development.

\section{Noticing, Caring, and Distancing}

We are aware, of course, of the irony or even the unreality or futility of discussing a group intervention at a time (at this writing and probably at the time of many readers' perusal of this article) in which social distancing is the omnipresent directive. We hope and expect that this problem is not as intractable as it appears at first glance, so that group well-child care can be undertaken even if meetings in person are not immediately feasible. We also hope that vaccine development and application will occur at a fast pace, so that restrictions on social activity will be safely eased or abandoned sooner than now appears likely. In that regard, the preceding discussion is grounded in the expectation that "in-person" group well-child care may be initiated before this article becomes stale.

At the same time, we would be remiss to ignore the immediate challenge and, as we noted supra, the difficulties that are likely to persist for years or even generations as community institutions are constrained or even closed. However, this is not a unanimous view. Although recognizing the severity of the current problems, some commentators (e.g., Brooks 2020a, 2020b) have suggested that experience in living amid the 
coronavirus pandemic may inculcate a new social consciousness in the American public - a hunger for connection, paired with a new spiritual maturity and an active desire to serve.

Consider Brooks' (2020b) recent observations in his column in the New York Times:

There's a new action coming into the world... I was on a Zoom call this week with 3000 college students hosted by the Veritas Forum. One question was on all their minds: What can I do right now?

I was on another Zoom call with 30 Weavers [i.e., exemplary community servants who weave the social fabric], and each one of them had begun some new activity to serve their neighbors. One lady was passing out vegetable seeds so families could plant their own vegetable gardens. Others are turning those tiny front-yard libraries into front-yard pantries. Some people are putting the holiday lights back up on their houses just to spread some cheer....

There's a new introspection coming into the world, as well. Everybody I talk to these days seems eager to have deeper conversations and ask more fundamental questions....

We are all assigned the task of confronting our own fear. I do not know about you, but I've had a pit of fear in my stomach since this started that has not gone away. But gradually you discover that you have the resources to cope as you fight the fear with conversation and direct action. A stronger self emerges out of the death throes of the anxiety....

So, yes, this is a meaningful moment. And it is this very meaning that will inspire us and hold us together as things get worse. In situations like this, meaning is a vital medication for the soul.

Noting that "the human impulse toward kindness is in full flower this dark spring," Loth (2020) wondered "whether these individualized acts of charity can be translated into a broader societal response":

Can the imprint of this disaster help us build more compassionate policies as we recover? We can stitch together the safety net more tightly and recreate an economy where fewer people need to use it - but only if we can hold on to the lesson of communal responsibility that this pandemic is teaching.

Hence, Loth's query is illustrative of a hope more than a prediction. In that regard, it is not our intent to denigrate acts of kindness toward either those who are suffering or those who work to ease such pain. Consideration of posts on Facebook (Weave Project, n.d.) in April 2020 about the pandemic-related contributions of Weavers gave no reason for doubt about the altruistic character and perhaps even the importance of their activities.

Speaking more generally, Loth (2020) noted the seemingly self-sustaining (mutually reinforcing) aspect of pandemic-related expressions of appreciation and support:

Donors get to help their favorite restaurants survive; who then keep their chefs and waiters employed; who then cook hot meals for doctors, nurses, and orderlies 
working on the medical front lines. Even the commitment to stay home and risk infecting other is a sacrifice made for the common good.

Although we concur that a norm of mutual assistance can be an important step toward a caring community (Principle 9 in Kimbrough-Melton and Melton 2015, and McLeigh et al., this issue), it is not self-evident that expressions of appreciation for people assuming personal risk while serving the public in a time of collective crisis will generalize easily in ordinary times to care for people who are chronically on or beyond the boundaries of the community (cf. Melton 2014). We are also unsure that the current craving for connection and impulse for service will be easily sustained, especially if many small businesses, civic clubs, religious organizations, and other community institutions are unable to recuperate from social distancing and if norms of "hunkering" in isolation become entrenched.

We are confident, however, that collective commitment to application of the Golden Rule is and will be key to fulfillment of children's right to personal security. We are further confident that normative change is critical to such a universal obligation, and we believe that it is likely that such a process will be even more challenging during and after the pandemic. However, Strong Communities did restore our faith in humanity. Although some modifications of the process may be required to adapt to current and forthcoming circumstances, we remain confident that communities (even those most in need) can be mobilized so that children grow up in safety, without fear, and with basic needs fulfilled. For families to be successful in protecting their children and for their neighbors to share in that success for their own children, people shouldn't have to ask (help should be natural), and no family should be left outside. Actualizing those principles is not easy, but it can and should be done.

\section{References}

1992 Los Angeles riots. (2020, April 20, 22:07). In Wikipedia. https://en.wikipedia.org/wiki/1992_Los_ Angeles_riots

Agrawai, N. (2020, April 7). The coronavirus could cause a child abuse epidemic. New York Times. https://www.nytimes.com/2020/04/07/opinion/coronavirus-child-abuse.html. Accessed 2020, Apr 20

Barry, F. D. (1994). A neighborhood-based approach: What is it? In G. B. Melton \& F. D. Barry (Eds.), Protecting children from abuse and neglect: Foundations for a new national strategy (pp. 14-39). New York: Guilford.

Bellah, R. N., Madsen, Sullivan, W. M., Swidler, A., \& Tipton, S. M. (2008). Habits of the heart: Individualism and commitment in American life (3rd ed.). Berkeley: University of California Press (Original work published 1985).

Belsky, J. (1980). Child maltreatment: An ecological integration. American Psychology, 35, 320-335.

Ben-Arieh, A., McDonell, J., \& Attar-Schwartz, S. (2009). Safety and home-school relations as indicators of child well-being: Whose perspective counts? Social Indicators Research, 90, 339-349.

Berman, J. J. (2020). Flexibility and creativity: Critical elements in prevention of child maltreatment. International Journal on Child Maltreatment: Research, Policy, and Practice, 3.

Berman, J. J., Murphy-Berman, V., \& Melton, G. B. (2008). Strong communities: What did participants actually do? Family \& Community Health, 31, 126-135.

Blanks, A. (2020, April 20). Child sexual, physical abuse cases are getting worse in Pensacola as quarantine drags on. Pensacola News-Journal. https://www.pnj.com/story/news/2020/04/20/coronavirus-childsexual-physical-abuse-cases-pensacola-getting-worse/5154200002/. Accessed 2020 April 20

Brooks, D. (2020a, March 19). Screw this virus! We had to be set apart in order to feel together. New York Times. https://nyti.ms/2J1lhpX. Accessed 2020 March 19 
Brooks, D. (2020b, March 26). The moral meaning of the plague: The virus is a test. We have the freedom to respond. New York Times. https://nyti.ms/2UjewWZ. Accessed 2020 March 26

Christ, S. L., \& Schwab-Reese, L. M. (2020). Shedding the constraints of formal systems of research on child maltreatment through high-quality measurement and broad population surveys. International Journal on Child Maltreatment: Research, Policy, and Practice, 3.

Cochran, M., \& Woolever, F. (1983). Beyond the deficit model: The empowerment of parents with information and informal supports. In S. Seigel \& L. Laosa (Eds.), Changing families (pp. 225-246). New York: Plenum.

Coker, T. R., Moreno, C., Shekelle, P. G., Schuster, M. A., \& Chung, P. J. (2014). Well-child care clinical practice redesign for serving low-income children. Pediatrics, 134, e229-e239.

Colen, C. G., Ramey, D. M., \& Browning, C. R. (2016). Declines in crime and teen childbearing: Identifying potential explanations for contemporaneous trends. Journal of Quantitative Criminology, 32, 397-426.

Committee on Child Maltreatment Research, Policy, and Practice for the Next Decade, Phase 2, Petersen, A. C., Joseph, J., \& Feit, M. (2014). New directions in child abuse and neglect research. Washington: National Academy Press.

Committee on Obstetric Practice. (2018, March). Group prenatal care. American College of Obstetricians and Gynecologists. https://acog.org/clinical/clinical-guidance/committee-opinion/articles/2018/03/groupprenatal-care

Convention on the Rights of the Child, (1989), G.A. Res. 44/25, U.N. GAOR Supp. 49 at 165, U.N. Doc. $\mathrm{A} / 44 / 736$.

Couloumbis, A. (2020, April 1). Calls to Pa.'s child-abuse hotline fell sharply during first weeks of the coronavirus: Here's why that's bad news. Spotlight PA. https://www.spotlightpa.org/news/2020/04 /pennsylvania-coronavirus-childline-child-abuse-hotline-family-stress/. Accessed 2020 April 1

Coulton, C. J., Korbin, J. E., \& Su, M. (1999). Neighborhoods and child maltreatment: A multi-level study. Child Abuse \& Neglect, 12, 1019-1040.

Daro, D. (2005). Community partnerships for protecting children: Phase II outcome evaluation. Chicago: Chapin Hall at the University of Chicago.

Davis, L, \& Parker, K. (2019, August 15). A half-century after "Mister Rogers” debut, 5 facts about neighbors in U.S. FactTank: News in the Numbers. Accessed 2019 August 15

Dignan, C. (2020, April 20). Social distancing leads to decline in reporting of child abuse amid coronavirus pandemic, CT experts say. New Haven Register. https:/www.nhregister.com/news/coronavirus/article/Socialdistancing-leads-to-decline-in-reporting-15212903.php\#photo-19281752. Accessed 2020 April 20

Finkelhor, D., \& Jones, L. (2006). Why have child maltreatment and child victimization declined? Journal of Social Issues, 62, 685-716.

Finkelhor, D., Saito, K., \& Jones, L. (2015). Updated trends in child maltreatment, 2013. Durham: University of New Hampshire, Crimes against Children Research Center.

Garbarino, J., \& Kostelny, K. (1992). Child maltreatment as a community problem. Child Abuse \& Neglect, $16,455-464$.

Garg, A., Toy, S., Tripodis, Y., Silverstein, M., \& Freeman, E. (2015). Addressing social determinants of health at well child visits: A cluster RCT. Pediatrics, 135, e296-e234.

Giovanni, J., \& Billingsley, A. (1970). Child neglect among the poor: A study of parental adequacy in families of three ethnic groups. Child Welfare, 49, 196-204.

Gold, J. (2019, May 30). The unexpected perk of my group pregnancy care: New friends. Kaiser Health News. https://khn.org/news/the-unexpected-perk-of-my-group-pregnancy-care-new-friends/. Accessed 2019 May 30

Hashima, P. Y., \& Melton, G. B. (2008). "I can conquer a mountain": Ordinary people who provide extraordinary community service. Family \& Community Health, 31, 162-172.

Haski-Leventhal, D., \& McLeigh, J. D. (2009). Firefighters volunteering beyond their duty: An essential asset in American rural communities. Journal of Rural and Community Development, 4(2), 80-92.

Haski-Leventhal, D., Ben-Arieh, A., \& Melton, G. B. (2008). Between neighborliness and volunteerism: Participants in the Strong Communities initiative. Family \& Community Health, 31, 150-161.

Haskins, R., Dodge, K. A., \& Daro, D. (2019, Spring). Achieving broad-scale impacts for social programs [Policy brief]. The Future of Children

Horner, S. (2020, April 16). Counties receiving fewer reports of child abuse amid coronavirus, but staff say it's not because of fewer incidents. Pioneer Press. https://www.twincities.com/202/04/16/mn-coronaviruschild-abuse-reports-domestic-violence/. Accessed 2020 April 16

Jack, G. (2000). Ecological influences on parenting and child development. British Journal of Social Work, $30,703-720$. 
Jonson-Reid, M., Drake, B., Cobetto, C., \& Ocampo, M. G. (2020, April 14). Child Abuse Prevention Month in the context of COVID-19. Washington University in St. Louis, Center for Innovation in Child Maltreatment Policy, Research, and Training. https://icm.wustl.edu/child-abuse-prevention-month-inthe-context-of-covid-19/. Accessed 2020 April 14

Katz, C., McLeigh, J. D., \& Ben-Arieh, A. (2019). Reflections on the traditional role of social workers in child protection: Lessons learned from the Strong Communities initiative in Israel. International Journal on Child Maltreatment: Research, Policy, and Practice, 2, 199-210.

Kempe, C. H. (1978). Sexual abuse, another hidden pediatric problem: The 1977 C. Anderson Aldrich Lecture. Pediatrics, 62, 382-389.

Kempe, C. H., Silverman, F. N., Steele, B. F., Droegemuller, W., \& Silver, H. K. (1962). The battered-child syndrome. Journal of the American Medical Association, 181, 17-24.

Kim, B. (2015). Community interaction and child maltreatment. Child Abuse \& Neglect, 41, 146-157.

Kimbrough-Melton, R. J., \& Melton, G. B. (2015). "Someone will notice, and someone will care": How to build Strong Communities for Children. Child Abuse \& Neglect, 41, 67-78.

Krugman, R. D. (2019). Ending gaze aversion toward child abuse and neglect. Health Affairs, 38, 1,762-1, 765.

Levine, P. (2013). We are the ones we have been waiting for: The promise of civic renewal in America. New York: Oxford University Press.

Limber, S. P., \& Kowalski, R. M. (2020). How schools often make a bad situation worse. International Journal on Child Maltreatment: Research, Policy, and Practice, 3.

Loranger, M. (2020, April 20). Child abuse reports drop during coronavirus schools shutdown —and it's not good news. South Coast Today. https://www.southcoasttoday.com/opinion/20200420/your-view-childabuse-reports-drop-during-coronavirus-schools-shutdown\%2D\%2D\%2D\%2Dand-its-not-good-news. Accessed 2020 April 20

Loth, R. (2020, April 24). Can we hold on to the lesson of communal responsibility that the coronavirus pandemic is teaching? Boston Globe. https://www.bostonglobe.com/2020/04/24/opinion/can-we-canhold-lesson-communal-responsibility-that-coronavirus-pandemic-is-teaching/. Accessed 2020 April 24

Maguire-Jack, K., \& Font, S. A. (2017). Intersections of individual and neighborhood disadvantage: Implications for child maltreatment. Children and Youth Services Review, 72, 44-51.

Maguire-Jack, K., \& Showalter, K. (2016). The protective effect of neighborhood social cohesion in child abuse and neglect. Child Abuse \& Neglect, 52, 29-37.

Mathews, B. (2015). Mandatory reporting laws: Their origin, nature, and development over time. In B. Mathews \& D. C. Bross (Eds.), Mandatory reporting laws and the identification of severe child abuse and neglect (pp. 3-25). Dordrecht: Springer.

McDonell, J. R., \& Melton, G. B. (2008). Toward a science of community intervention. Family \& Community Health, 31, 113-125.

McDonell, J. R., Ben-Arieh, A., \& Melton, G. B. (2015). Strong Communities for Children: Results of a multi-year community-based initiative to protect children from harm. Child Abuse \& Neglect, 41, 79-96.

McLeigh, J. D., McDonell, J. R., \& Melton, G. B. (2015). Community differences in the implementation of Strong Communities for Children. Child Abuse \& Neglect, 41, 97-112.

McLeigh, J. D., Katz, C., Davidson-Arad, B., \& Ben-Arieh, A. (2017). The cultural adaptation of a community-based child maltreatment prevention initiative. Family Process, 56, 393-407.

McLeigh, J. D., Grate, P., Cole, D., \& Melton, G. B. (2020). One person can make a difference: Stories of Strong Communities and their outreach workers. International Journal on Child Maltreatment: Research, Policy, and Practice, 3

Melton, G. B. (1992). It's time for neighborhood research and action. Child Abuse \& Neglect, 16, 909-913.

Melton, G. B. (1993). Is there a place for children in the new world order? Notre Dame Journal of Law, Ethics, and Public Policy, 7, 491-532.

Melton, G. B. (2005). Mandated reporting: A policy without reason. Child Abuse \& Neglect, 29, 9-18.

Melton, G. B. (2009). How Strong Communities restored my faith in humanity: Children can live in safety. In K. A. Dodge \& D. L. Coleman (Eds.), Preventing child maltreatment: Community approaches (pp. 82101). New York: Guilford.

Melton, G. B. (2010). "To such as these, the kingdom of heaven belongs": Religious faith as foundation for children's rights. In J. Garbarino \& G. Sigman (Eds.), Children's right to a healthy environment (pp. 330). New York: Springer.

Melton, G. B. (2013). A swan song (or a fanfare): Some thoughts of an institute director after 30 years of service. American Journal of Orthopsychiatry, 83, 1-10.

Melton, G. B. (2014). Hospitality: Transformative service to children, families, and communities. American Psychologist, 69, 761-769. 
Melton, G. B., \& Anderson, D. (2008). From Safe Sanctuaries to Strong Communities: The role of communities of faith in child protection. Family \& Community Health, 31, 173-185.

Melton, G. B., \& Thompson, R. A. (2002). The conceptual foundation: Why child protection should be neighborhood-based and child-centered. In G. B. Melton, R. A. Thompson, \& M. A. Small (Eds.), Toward a child-centered, neighborhood-based child protection system (pp. 3-27). Westport: Praeger.

Metrikin-Gold, B. D. (2015). Personal reflections about the work of the U.S. Advisory Board on Child Abuse and Neglect. Child Abuse \& Neglect, 41, 3-18.

Molnar, B. E., Beatriz, E. D., \& Beardslee, W. R. (2016). Community-level approaches to child maltreatment prevention. Trauma, Violence \& Abuse, 17, 387-397.

Murphy-Berman, V., Berman, J. J., \& Melton, G. B. (2008). Transformative change: An analysis of the evolution of special events within 3 communities. Family \& Community Health, 31, 136-149.

Murthy, V. (2020). Together: The healing power of human connection in a sometimes lonely world. New York: HarperCollins.

National Commission on Children. (1991). Beyond rhetoric: A new American agenda for children and families. Washington: U.S. Government Printing Office.

Pelton, L. H. (2015). The continuing role of material factors in child maltreatment and placement. Child Abuse \& Neglect, 41, 30-39.

Peterson, C., Florence, C., \& Klevens, J. (2018). The economic burden of child maltreatment in the United States, 2015. Child Abuse \& Neglect, 86, 178-183.

Pohl, C. D. (2011). Hospitality and the mental health of children. American Journal of Orthopsychiatry, 81, $482-488$.

Prime Minister's Office. (2018, October 16). PM launches Government's first loneliness strategy [Press release]. https://www.gov.uk/government/pm-launches-governments-first-loneliness-strategy. Accessed 2018 October 16

Putnam, R. D. (1995). Bowling alone: America's declining social capital. Journal of Democracy, 6, 65-78.

Putnam, R. D. (2000). Bowling alone: The collapse and revival of American community. New York: Simon \& Schuster.

Ross, L. (1977). The intuitive psychologist and his shortcomings: Distortions in the attribution process. In L. Berkowitz (Ed.), Advances in experimental social psychology (Vol. 10, pp. 173-220). New York: Academic Press.

Roygardner, D., Palusci, V., \& Hughes, K. N. (2020). Advancing prevention zones: Implementing community-based strategies to prevent child maltreatment and promote healthy futures. International Journal on Child Maltreatment: Research, Policy, and Practice, 3(1).

Rushton, F. E. (1998). Family support in community pediatrics: Confronting new challenges. Westport: Praeger.

Rushton, F. E., \& Kraft, C. (2013). Family support in the family-centered medical home: An opportunity for preventing toxic stress and its impact in young children. Child Abuse \& Neglect, 37(Supp), 41-50.

Rushton, F. E., Byrne, W., Darden, P. M., \& McLeigh, J. D. (2015). Enhancing child safety and well-being through pediatric group well-child care and home visitation: The Well Baby Plus Program. Child Abuse \& Neglect, 41, 182-189.

Sastry, A., \& Bates, K. G. (2017, April 26). When LA erupted in anger: A look back at the Rodney King riots. NPR. https:/www.npr.org/2017/04/26/524744989/when-la-erupted-in-anger-a-look-back-at-the-rodneyking-riots. Accessed 2017 April 26

Schmidt, S., \& Natanson, H. (2020, April 30). With kids stuck at home, ER doctors see more severe cases of child abuse. Washington Post. https://www,washingtonpost.com/education/2020/04/30/child-abusereports-coronavirus/. Accessed 2020 April 30

Schorr, L. (1988). Within our reach: Breaking the cycle of disadvantage. New York: Doubleday.

Stout, M. (2020, April 9). Reports of child abuse and neglect are plummeting across New England: That's not a good thing. Boston Globe. https://www.bostonglobe.com/2020/04/09/nation/reports-child-abuseneglect-are-plummetng-across-new-england-thats-not-good-thing/. Accessed 2020 April 9

"Suffering in silence": Worries mount over drop in reported child abuse cases. (2020). Axios. https://www. axios.com/child-abuse-coronavirus-stay-home-5e1e4439-a352-4b78-a3a8-81c26416ab8b.html (2020 April 19).

Thompson, R. A. (1995). Preventing child maltreatment through social support: A critical analysis. Thousand Oaks: Sage.

Thompson, R. A. (2015). Social support and child protection: Lessons learned and learning. Child Abuse \& Neglect, 41, 19-29.

Toqueville, A. (2004). Democracy in America (A. Goldhammer, Trans.). New York: Library of America (Original work published 1835 [Book 1] \& 1840 [Book 2]). 
Turner, J. R., \& Avison, W. R. (1985). Assessing risk factors for problem parenting: The significance of social support. Journal of Marriage and the Family, 47, 881-892.

Twenge, J. M., Campbell, W. K., \& Carter, N. T. (2014). Declines in trust in others and confidence in institutions among American adults and late adolescents, 1972-2012. Psychological Science, 25, 1,914-1, 923.

U.S. Advisory Board on Child Abuse and Neglect. (1990). Child abuse and neglect: Critical first steps in response to a national emergency. Washington: U.S. Government Printing Office.

U.S. Advisory Board on Child Abuse and Neglect. (1991). Creating caring communities: Blueprint for an effective federal policy on child abuse and neglect. Washington: U.S. Government Printing Office.

U.S. Advisory Board on Child Abuse and Neglect. (1993). Neighbors helping neighbors: A new national strategy for the protection of children. Washington: U.S. Government Printing Office.

U.S. Department of Health and Human Services, Administration for Children and Families, Administration on Children, Youth, and Families, Children's Bureau. (2020). Child maltreatment 2018. Washington: Author.

U.S. Department of Health and Human Services, Office of Adolescent Health. (2016). Trends in teen pregnancy and childbearing. Retrieved from https://www.hhs.gov/ash/oah

U.S. Department of Health and Human Services, Office of Human Development Services, Administration for Children, Youth, and Families, Children's Bureau, National Center on Child Abuse and Neglect. (1988). Study of national incidence and prevalence of child abuse and neglect: Study findings. Washington: Author.

Universal approaches to promoting healthy development [Special issue]. (2019). Future of Children, 29(1).

Vedantam, S. (2020, April 20). A social prescription why human connection is crucial to our health [Audio podcast episode; interview with former surgeon general V. Murthy]. In Hidden brain. NPR. https://one. npr.org/?sharedMediaid=83875183:8391598408utm_source=npr.newsletter\&utm_medium=email\&utm_ content $=20200426 \& u t n$. Accessed 2020 April 20

Venkatraman, S. (2020, March 27). Experts fear child abuse will increase with coronavirus isolation. NBC News. https:/www.nbcnews.com/news/us-news/experts-fear-child-abuse-will-increase-coronavirusisolation-n1170811. Accessed 2020 March 27

Weissbourd, B., \& Grimm, C. (1981). Family focus: Supporting families in the community. Children Today, $10(2), 6-11$.

Wolfe, D. A. (1985). Child-abusive parents: An empirical review and analysis. Psychological Bulletin, 97, $462-482$.

Zolotor, A. J., \& Runyan, D. K. (2006). Social capital, family violence, and neglect. Pediatrics, 117, 1124 1131.

Publisher's Note Springer Nature remains neutral with regard to jurisdictional claims in published maps and institutional affiliations.

\section{Affiliations}

\section{Gary B. Melton ${ }^{1,2} \cdot$ Jill D. McLeigh ${ }^{1,3}$}

1 The Kempe Center, University of Colorado Anschutz Medical Campus, Aurora, CO 80045, USA

2419 Hazel Grove Lane, Crozet, VA 22932, USA

3 Rees-Jones Center for Foster Care Excellence, Children's Health System of Texas, Dallas, TX 75235, USA 